\title{
12. PRELIMINARY ICHTHYOLITH BIOSTRATIGRAPHY, SOUTHWEST PACIFIC, DEEP SEA DRILLING PROJECT LEG 91 1
}

\author{
E. C. Winfrey, P. S. Doyle, and W. R. Riedel, Scripps Institution of Oceanography²
}

\begin{abstract}
Seventy meters of Cenozoic and Mesozoic pelagic clay cored at DSDP Sites 595 and 596 provide the basis for a preliminary analysis of ichthyolith biostratigraphy in the southwest Pacific. A most likely order of the more reliable ichthyolith events is compared with a synthesis of ichthyolith biostratigraphy in the North Pacific and with dated composite ranges. The resultant preliminary ichthyolith stratigraphy suggests that the Cenozoic is represented by the upper $20 \mathrm{~m}$ at Site 596 and 16 to $22 \mathrm{~m}$ at Site 595. Mixing of taxa precludes a clear recognition of the Cretaceous/Tertiary boundary at Site 595. The occurrence of 13 newly described subtypes is recorded in Mesozoic sediments at Sites 595 and 596 . These new subtypes and previously described Mesozoic forms may be useful for recognizing Mesozoic subdivisions when their occurrences in sequences dated by other microfossils are investigated.
\end{abstract}

\section{INTRODUCTION}

Approximately $70 \mathrm{~m}$ of Cenozoic and Mesozoic brown pelagic clay that were cored in the southwest Pacific Ocean at Deep Sea Drilling Project Sites $595\left(23^{\circ} 49.34^{\prime} \mathrm{S}, 165^{\circ}\right.$ $31.62^{\prime} \mathrm{W}$, water depth $\left.5614 \mathrm{~m}\right)$ and $596\left(23^{\circ} 51.20^{\prime} \mathrm{S}\right.$, $169^{\circ} 39.27^{\prime} \mathrm{W}$, water depth $5701 \mathrm{~m}$ ) provide the basis for the present ichthyolith study. Objectives for this investigation are twofold: first, to provide preliminary age determinations for the cored sediments using upper and lower limits of ichthyolith taxa selected as being relatively reliable; and second, to document new Mesozoic ichthyolith forms. Since this is a preliminary study, sample sizes are small (most are $20 \mathrm{~cm}^{3}$ ). Therefore, age determinations do not represent the "state-of-the-art" in ichthyolith stratigraphy.

Before this expedition, the precise age of the oldest part of the sediment to be cored on Leg 91 was not known, but it was suspected to be Mesozoic. Shipboard interpretation of magnetic anomalies indicated that Site 595 is located on Magnetic Anomaly M-29, suggesting an age of Jurassic (Callovian) for the basement (see Site 595 chapter, this volume). Thus, sediments above the basement may be the oldest yet recovered by drilling in the Pacific. These sediments are zeolitic to metalliferous, brown pelagic clays, interbedded with porcellanite and cherts in the lower $30-70 \mathrm{~m}$. Other than ichthyoliths, which are present throughout the cores, microfossils are limited to rare foraminifers and poorly preserved radiolarians, the latter being common in the lower, chert-bearing, pelagic clays. Hence, ichthyoliths provide the means for biostratigraphic age determination, particularly in the Cenozoic. Mesozoic ichthyoliths have not been studied extensively (Ramsey et al., 1976). However, this study

\footnotetext{
${ }^{1}$ Menard, H. W., Natland, J., Jordan, T. H., Orcutt, J. A., et al., Init. Repts. DSDP, 91: Washington (U.S. Govt. Printing Office).

2 Address: Scripps Institution of Oceanography (A-012), University of California, San Diego, La Jolla, CA 92093.
}

allows us to document the occurrence of some known and some new Mesozoic ichthyoliths for future comparison.

\section{MATERIALS AND METHODS}

Hole 595A was rotary-cored to basement with only $40 \%$ recovery. Sediments in the upper $40 \mathrm{~m}$ of Hole 596 were hydraulic-piston-cored, whereas the lower $31 \mathrm{~m}$ were rotary-cored using an extended core barrel. In Hole 596A, $4 \mathrm{~m}$ of the oldest sediment were recovered in a single core terminating $\sim 1 \mathrm{~m}$ above basement. Coring in Hole 596B recovered an interval between 24.7 and $34.3 \mathrm{~m}$ missed in Hole 596 .

Sixty-six samples were taken at widely spaced intervals (average $1.5 \mathrm{~m}$ ) in Holes 596, 596A, 596B, and the upper $26 \mathrm{~m}$ of Hole 595A. Poor recovery below $26 \mathrm{~m}$ in Hole 595A permitted only six samples to be taken at intervals of from 3 to $5 \mathrm{~m}$. Because this is a preliminary study, only a few samples were the typical $50 \mathrm{~cm}^{3}$ size used in ichthyolith studies; most were small, only $20 \mathrm{~cm}^{3}$ in volume. Dry weight varied from about 3.5 to $31 \mathrm{~g}$ (Tables 1, 2).

Samples were processed following the method described by Edgerton et al. (1977), except that residues were passed through both 63and $44-\mu \mathrm{m}$ screens. Balsam slides were prepared from each size fraction. Preliminary shipboard samples from Hole 596 were processed to assess their potential for ichthyoliths. Residues of these preliminary samples were collected on a $44-\mu \mathrm{m}$ screen and not separated into two size fractions.

The total number of triangular forms with tip preserved was counted in all $63-\mu \mathrm{m}$ and preliminary balsam slides (Tables 1,2 ), the latter of which contain the entire fraction coarser than $44 \mu \mathrm{m}$. Total numbers of triangular forms in a sample varied from none to thousands, but were conmonly in the hundreds. The number of triangular ichthyoliths per gram (dry wt) for each sample is recorded (Tables 1,2) in order to quantify ichthyolith concentration.

All previously described subtypes (except Flexed triangle 102-112, Flexed triangle 115-118, and Flexed narrow triangle 120-128, which are undergoing taxonomic revision) were identified, counted, and recorded in all $63-\mu \mathrm{m}$ and preliminary balsam slides (Tables 1,2 ). Those subtypes found are recorded under "List of Taxa Present," those not found under "List of Taxa Not Present," in the Appendix to this chapter. New subtypes described herein were identified in all samples from Section 595A-9-1 to Section 595A-2-2 from Section 596-9-1 to Section 596-3-3, and from the entire section in Holes 596A and 596B.

\section{STRATIGRAPHY}

\section{Ichthyolith Concentrations}

Ichthyoliths are present throughout the sequence in Hole 595A, with peak abundances of triangular forms 
E. C. WINFREY, P. S. DOYLE, W. R. RIEDEL

Table 1. Stratigraphic distribution of previously described ichthyolith subtypes from Hole 595A.

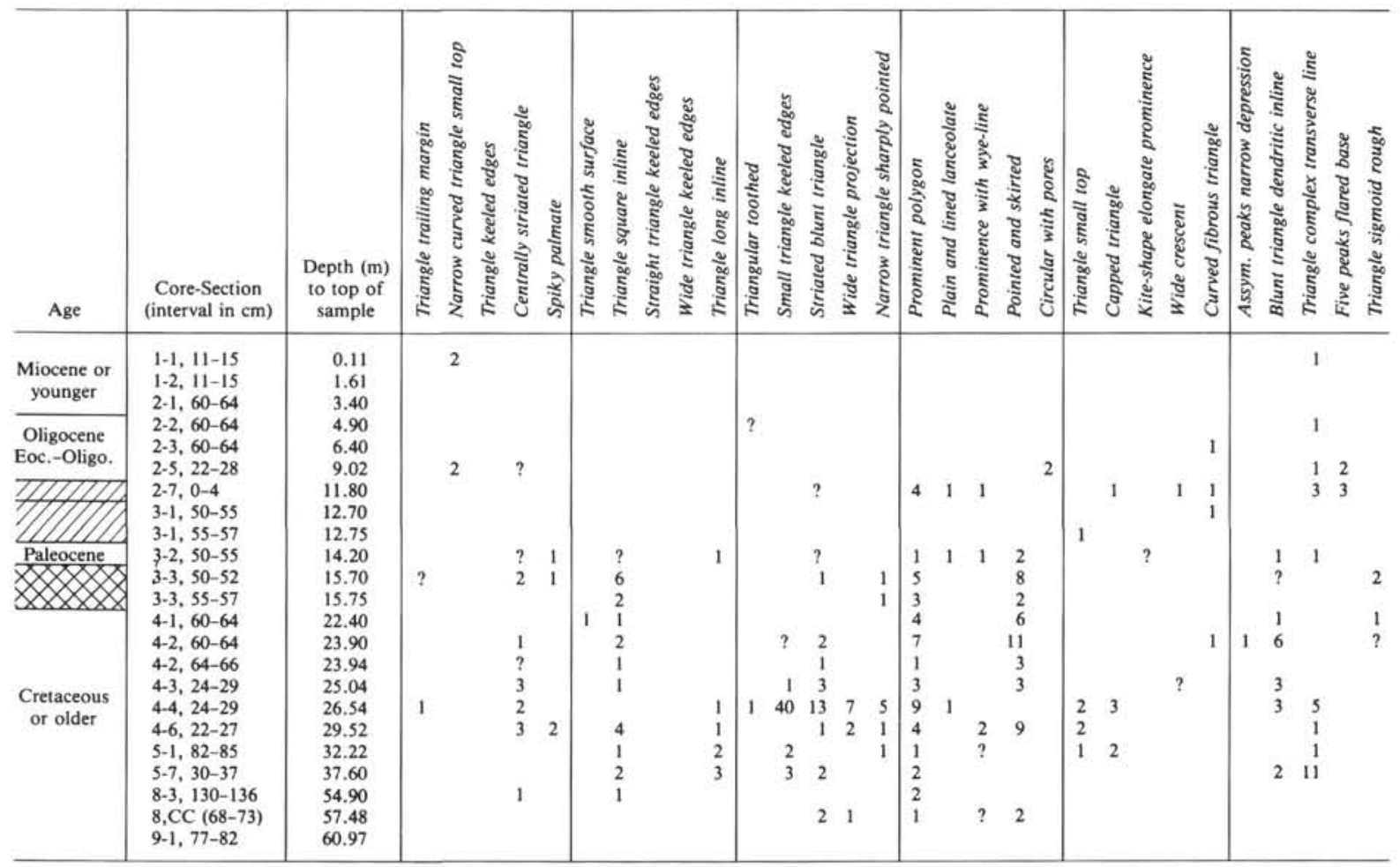

Note: Flexed narrow triangle 120-128, Flexed triangle 102-112, and Flexed triangle 115-118 not included. Question marks indicate broken but recognizable specimens. Subtypes are arranged in order of first occurrence in GPC-3. Ages are based on ichthyoliths. Cross-hachuring indicates reworking of taxa, hachuring indicates uncertainty of boundary placement, and line within the hachuring indicates a likely placement of the boundary.

Table 1 (continued).

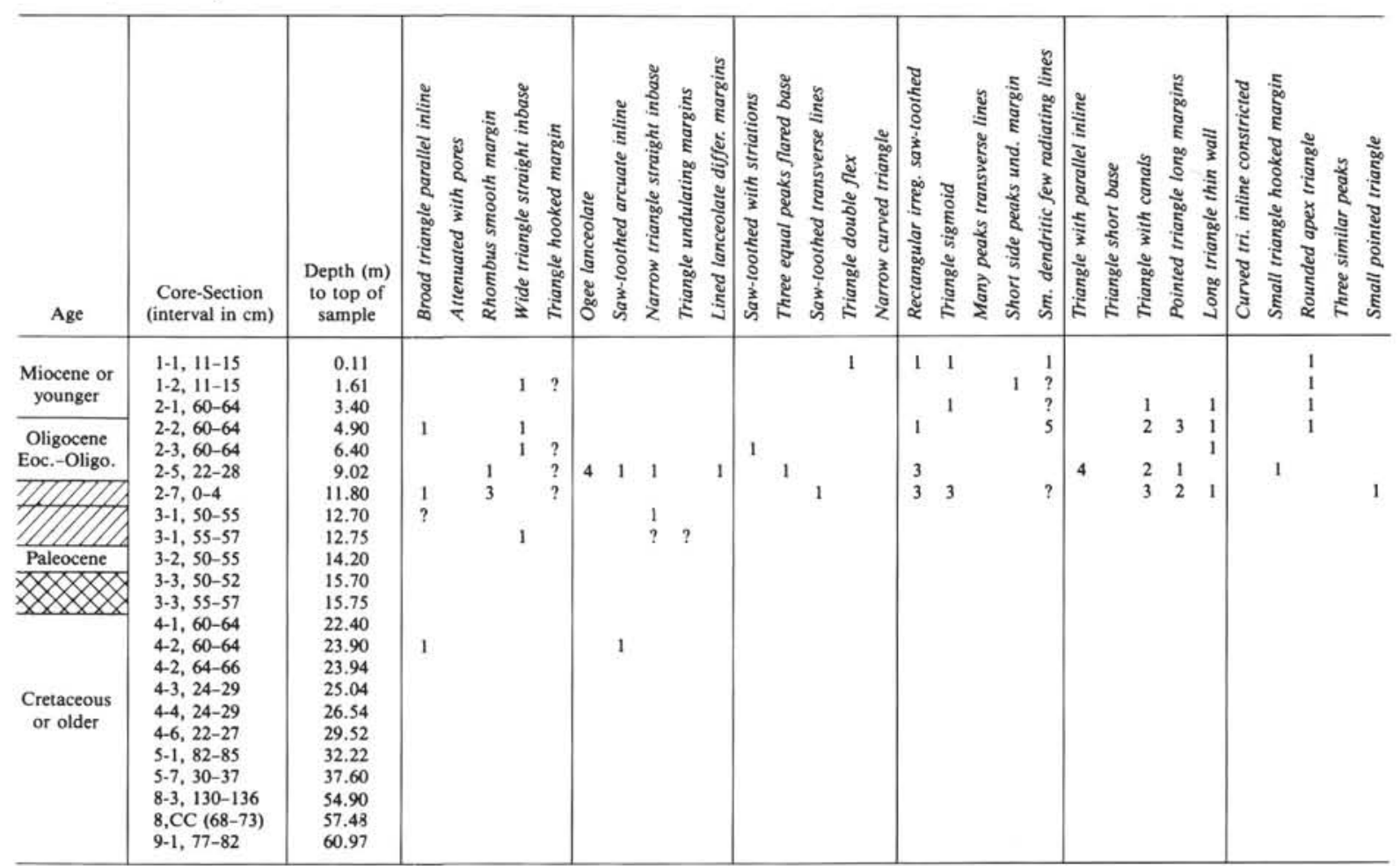


Table 1 (continued).

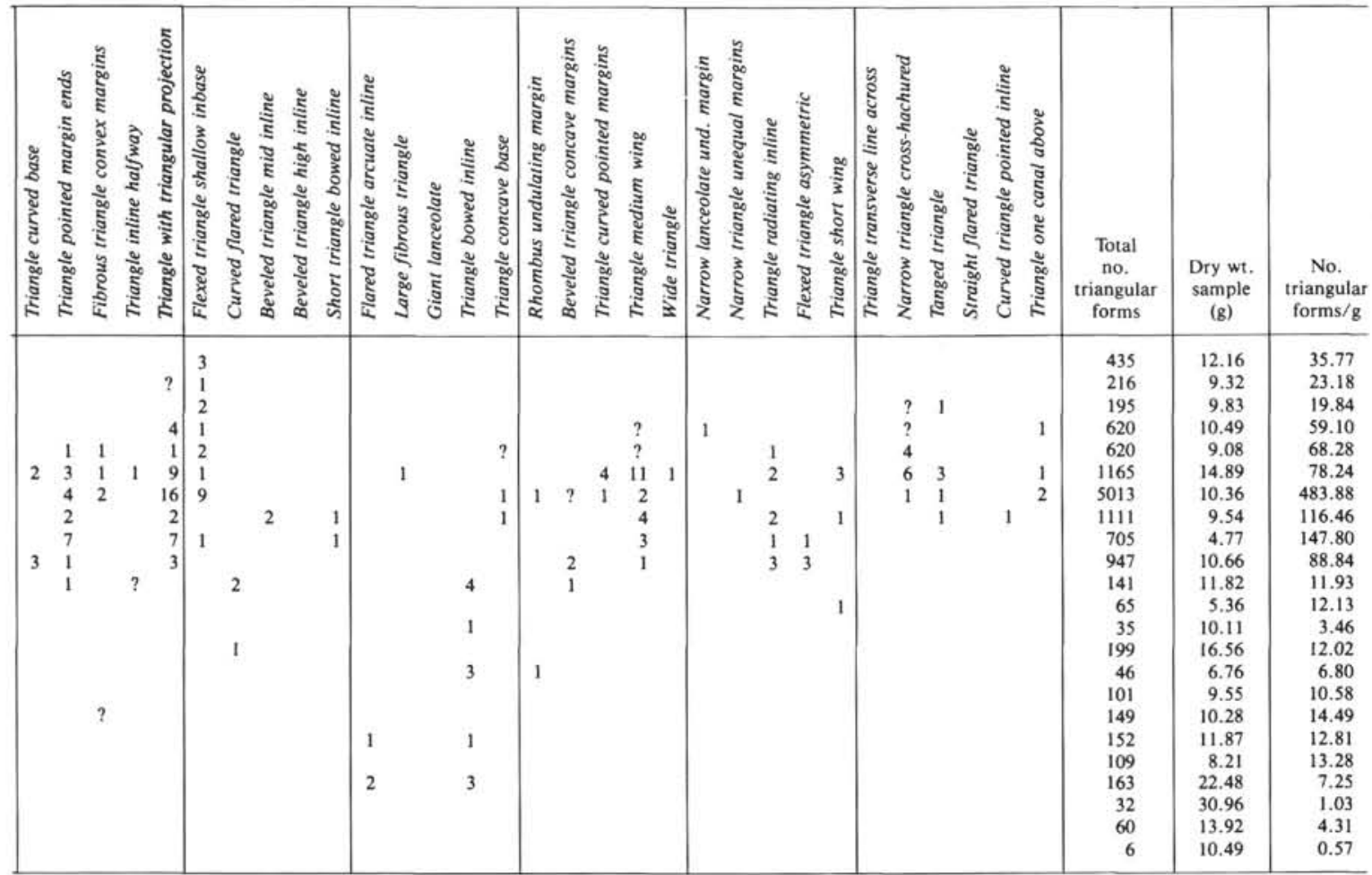

Table 1 (continued).

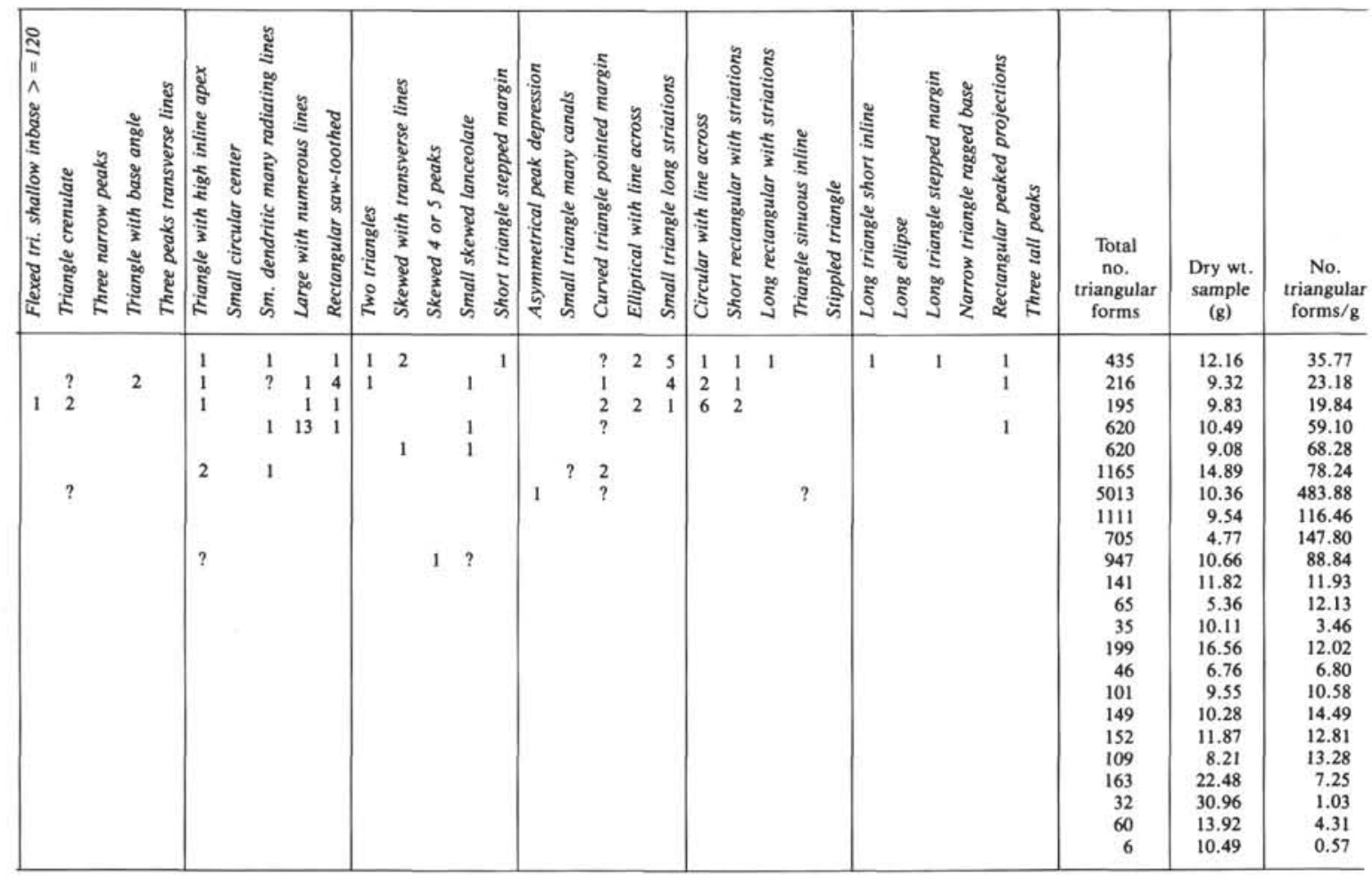


Table 2. Stratigraphic distribution of previously described ichthyolith subtypes at Site 596.

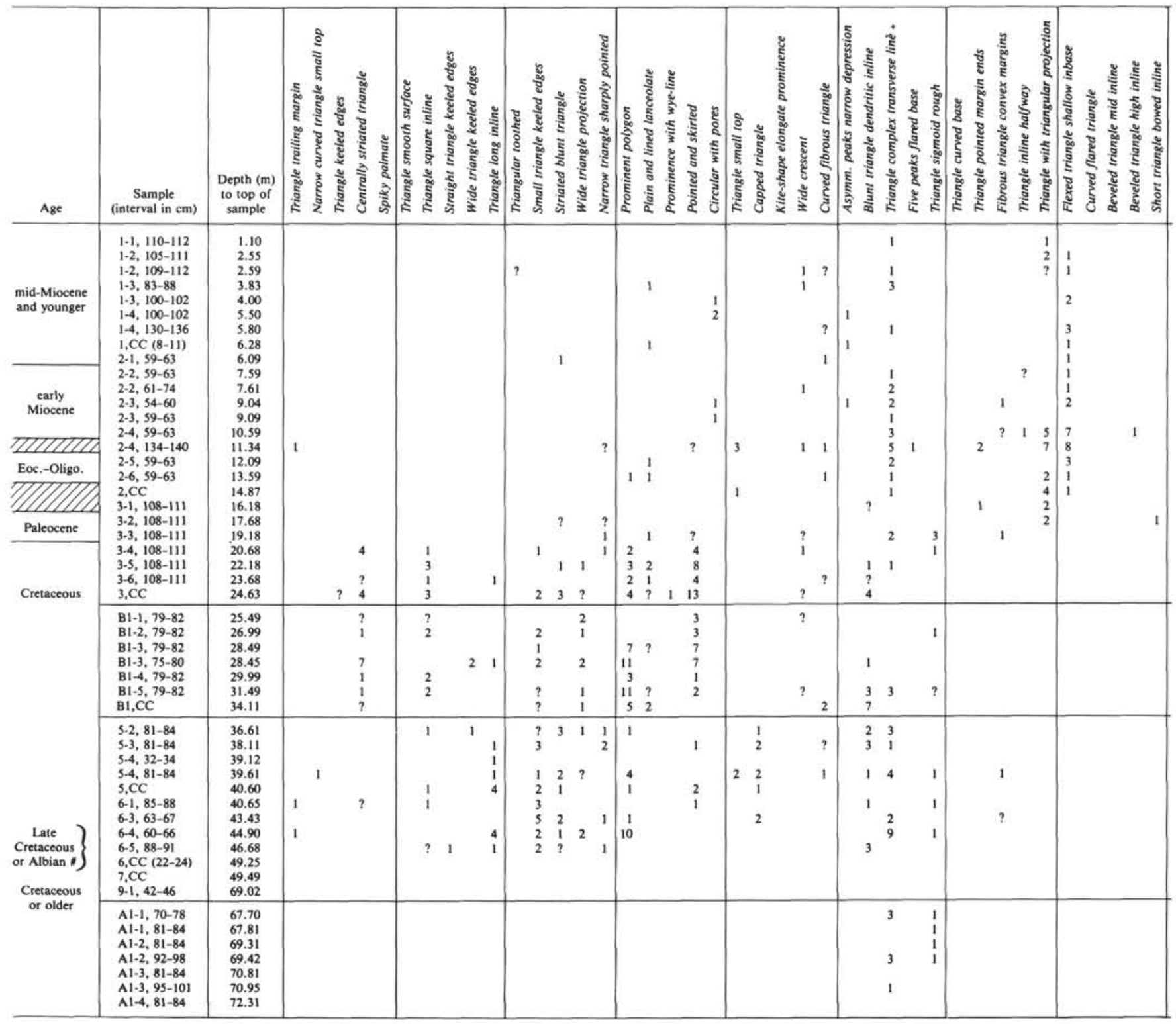

Note: Flexed narrow triangle 120-128, Flexed triangle 102-112, and Flexed triangle $115-118$ not included. Subtypes are arranged in order of first occurrence in GPC-3. Question marks indicate broken but recognizable specimens. A or B before sample number indicates samples from Holes 596A or 596B, respectively. Ages are based on ichthyoliths except as noted by ", where sample is dated by radiolarians. Hachuring indicates uncertainty of boundary placement.

asterisks indicate that these were shipboard samples in which the slides contain ichthyoliths greater than $44 \mu \mathrm{m}$.

bry weight not recorded; concentrations cannot be determined.

at $11.80 \mathrm{~m}$ (Section 595A-2-7), and, to a lesser extent, at $12.70,12.75$, and $14.20 \mathrm{~m}$ (Sections 595A-3-1 and -2) (Fig. 1). They are common to rare below $15 \mathrm{~m}$.

At Site 596 ichthyoliths occur in concentrations of 7-100 triangular ichthyoliths/g (dry wt.). Peak abundances of triangular ichthyoliths occur at 10.59 and $11.34 \mathrm{~m}$ (Section 596-2-4), and at $17.68 \mathrm{~m}$ (Section 596-3-2) (Fig. 2). In the interval below $20 \mathrm{~m}$, there are 0-30 triangular ichthyoliths/g (dry wt.). The near-absence of ichthyoliths below $47 \mathrm{~m}$ (Fig. 2) might be considered atypical for brown pelagic clays, since ichthyoliths are almost ubiquitous and common. The position of these clays above basalt might suggest that vent activity caused ichthyoliths to dissolve. However, comparison with other se- quences of pelagic clay close to basaltic basement (Kaneps et al., 1981; Gottfried et al., in press) does not reveal similar low concentrations of ichthyoliths. We should note that ichthyoliths of this age (Late Cretaceous or older) and within this lithology have not been examined prior to the present study. Therefore, low concentrations may reflect low productivity of open-ocean fishes during this time.

These ichthyolith concentration patterns with age (Figs. 1,2) are somewhat comparable to patterns elsewhere (Doyle and Riedel, 1979a, 1980, 1981), with peaks occurring in the Paleocene and Eocene. However, the peak in the early Miocene of Hole 596 (Fig. 2 at $11.34 \mathrm{~m}$ ) has not been observed elsewhere. The stratigraphic resolu- 
Table 2 (continued).

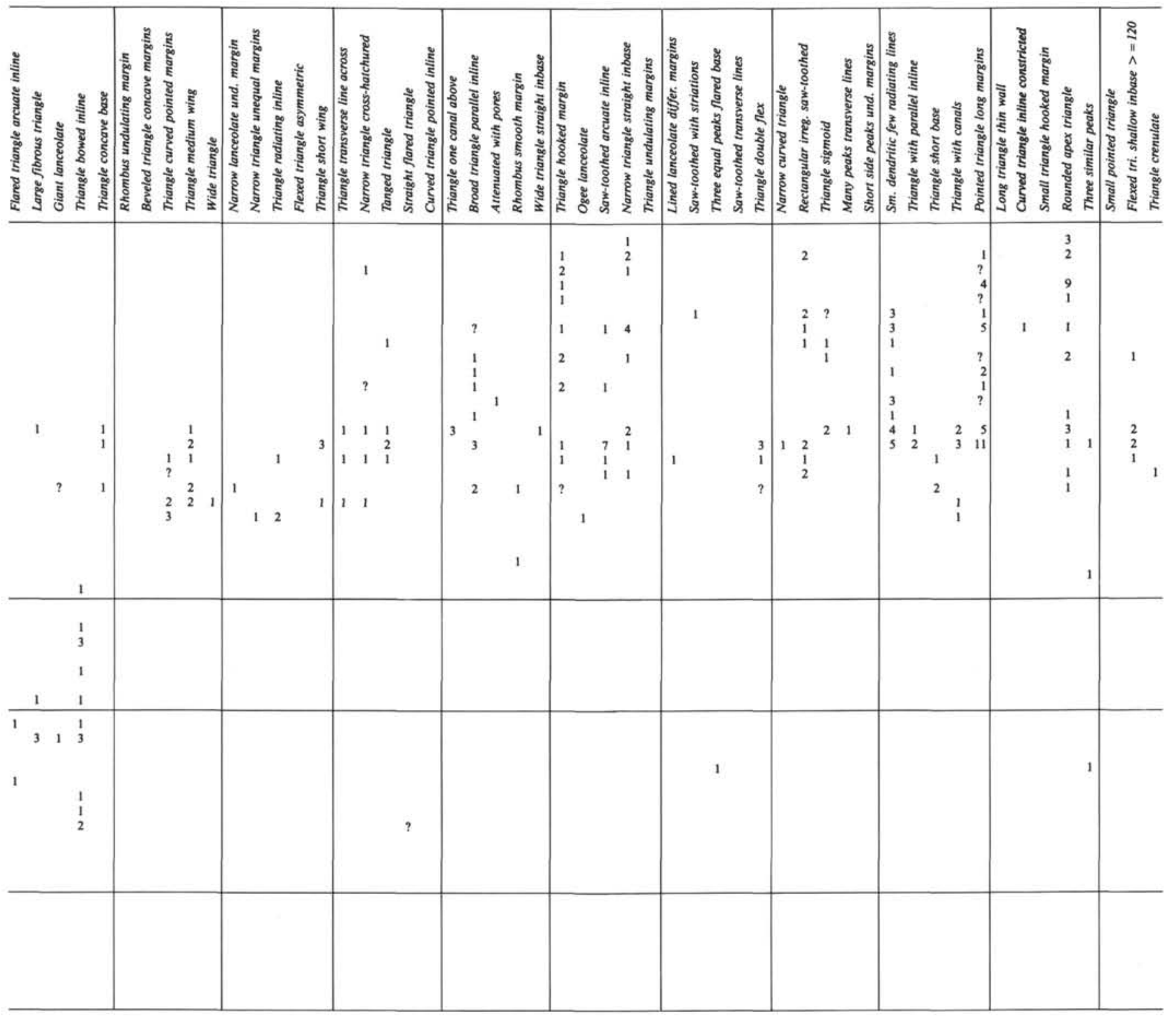

tion attainable with ichthyoliths is not yet sufficient to permit conversion of these concentrations to rates of accumulation as Shackleton et al. (1984) have deduced from sediments dated with other microfossils.

\section{Age Determinations}

Previous work has documented ichthyolith ranges in samples dated by other pelagic microfossils (Doyle et al., 1974, 1978; Dengler et al., 1975; Dunsworth et al., 1975; Ramsey et al., 1976). Several hundred of these samples from the Pacific localities indicated on Fig. 3 have been compiled into a data base of ichthyolith ranges which are correlated primarily by the nannofossil zonation of Okada and Bukry (1980). We have been able to apply this ichthyolith stratigraphy to sequences of pelagic clays lacking other microfossils (Doyle and Riedel, 1979b, 1985b; Kaneps et al., 1981; Gottfried et al., 1985; Tway et al., 1985). In these clays, ichthyoliths usually provide the only means for age determinations, the resolution being to about the level of epoch. In the present study, age precision is less, in part because sample size is small.

Not all earliest and latest occurrences (events) of ichthyoliths are equally reliable in determining ages. Similar difficulties have been encountered with other microfossils, but are especially acute with ichthyoliths because of their low abundances. In order to judge the reliability of these events, a set of factors pertaining to taxon limits of radiolarians has been developed (Riedel and Westberg, 1982; Westberg and Riedel, 1982). Gottfried et al. (1984) and Doyle and Riedel (1985b) used modified versions of these factors to evaluate ichthyolith events. At Sites 595 and 596 we have also attempted to evaluate all ichthyolith events using a set of five factors: (1) constancy of taxon presence near event is evaluated by considering occurrences in the four samples above an earliest occurrences or below a latest occurrence, (2) number of a 
Table 2 (continued).

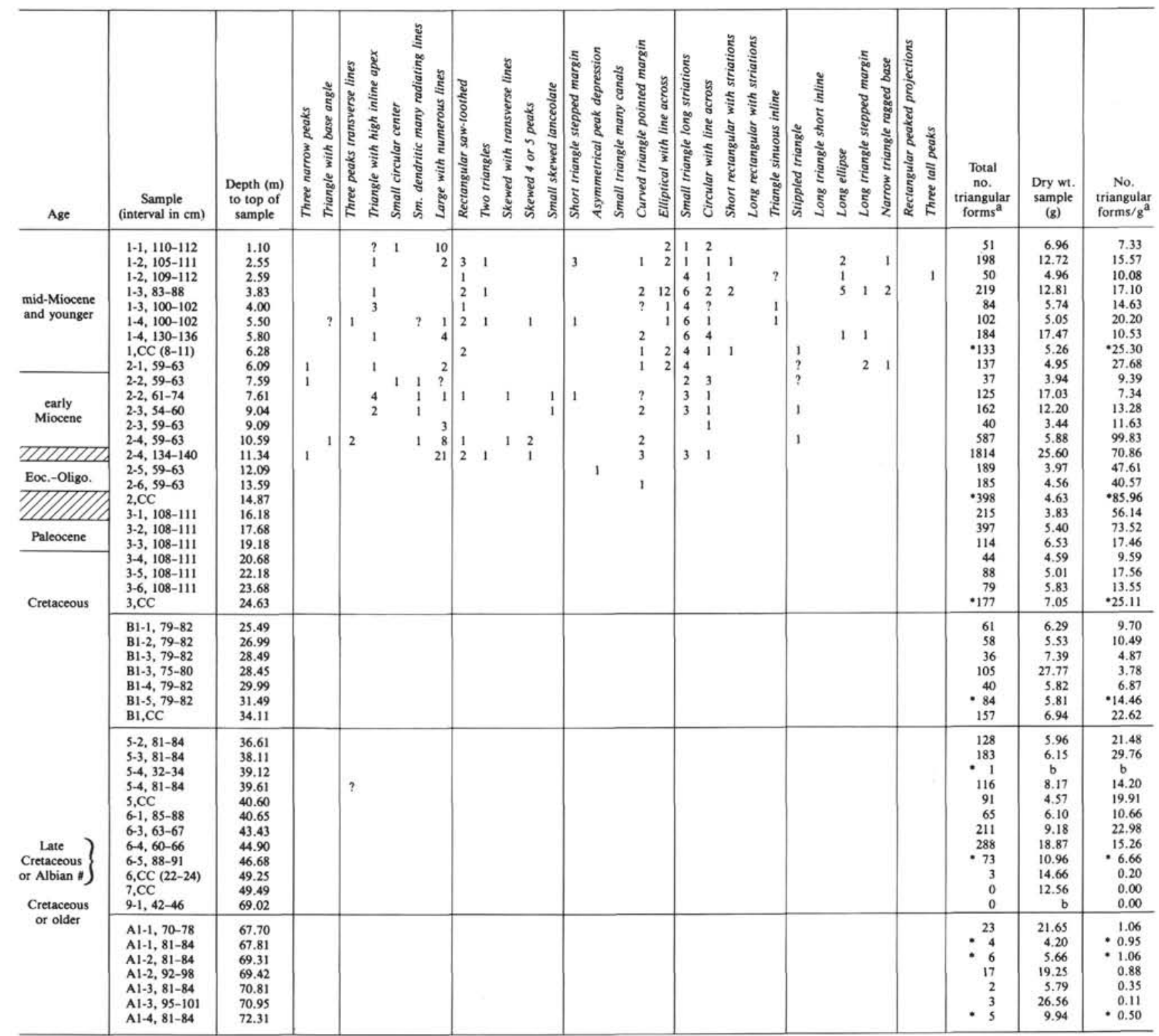

taxon in samples recording an event measures the strength of signal, (3) ease of recognition of taxa is evaluated subjectively by the worker, (4) number of samples above an earliest occurrence or below a latest occurrence is a measure of confidence that this is an event and not just a function of the upper and lower limits of sampling, and (5) evolutionary type of event is morphotypic for all ichthyolith subtypes. Each factor on which the index of reliability is based can have a range of associated values between 0 and 1 (Table 3). Gottfried et al. (1984) and Doyle and Riedel (1985b) used factors similar to 1, 2, and 3 , but with slightly different responses and scales of values. Gottfried et al. (1984) used an additional factor that evaluated geographic limits of a taxon. However, not enough is known about the distributions of ichthyoliths considered in this study to evaluate this factor satisfactorily. Values for the response to all the factors are multiplied together. The $n$th root $(n=$ number of relia- bility factors) of this product results in a reliability index for each event.

$$
\text { reliability index }=\sqrt[n]{f_{1} \times f_{2} \times \ldots \times f_{n}},
$$

where

$$
\begin{aligned}
& f=\text { value for reliability factor } \\
& n=\text { number of factors }
\end{aligned}
$$

By taking the $n$th root, we keep the index between 0 and 1 , and avoid exceedingly small numbers, particularly when using many factors.

In an effort to correlate sites and assign ages to cored sediments, events common to both Sites 595 and 596 with reliability indices in the top third (index $>0.40$ ) were selected. These chosen events were then arranged in a most likely order, and compared with dated ichthyolith 


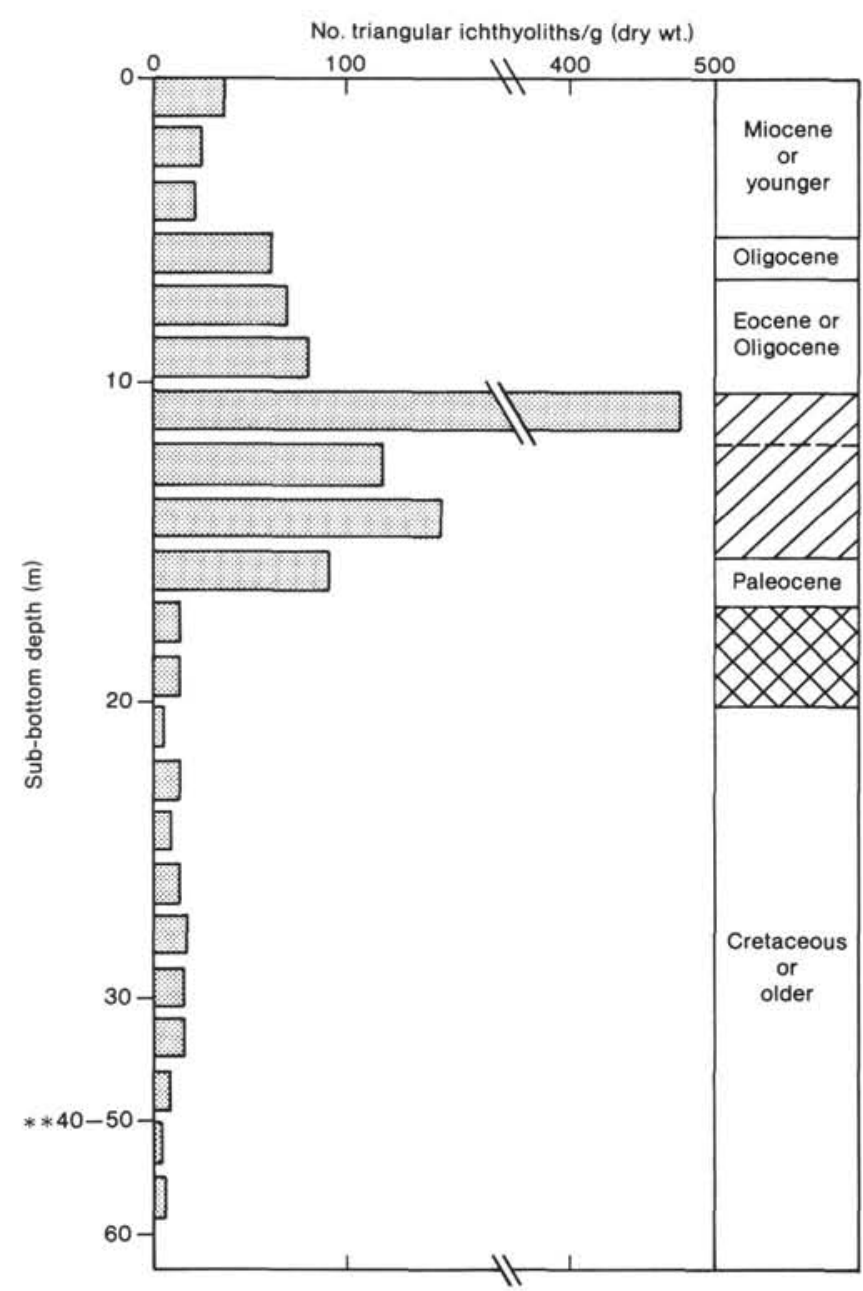

Figure 1. Concentration of ichthyoliths with depth in Hole 595A. Bars represent the concentration at each sample. Depths are not evenly spaced, especially below $30 \mathrm{~m}$ (indicated by double asterisks), where poor recovery allowed for only sparse sampling. Ages of samples, determined by ichthyoliths, are marked. Hachuring indicates uncertainty of boundaries, with dashed line suggesting a likely boundary. Cross-hachuring indicates that taxa of different ages are mixed.

ranges from the Pacific and probabilistic ranges from the North Pacific (Doyle and Riedel, in press, b) (Table 4). In determining ages for these events, we gave primary importance to North Pacific age assessments of ichthyolith events. However, comparing these selected ichthyolith events with their most probable ages in the North Pacific offers little evidence for age assessments of the earliest occurrences of Rectangular irregularly saw-toothed, Tanged triangle, Flexed triangle shallow inbase, Narrow triangle straight inbase, Rounded apex triangle, and Narrow triangle cross-hachured (Table 4). Comparison with dated Pacific samples shows an irregular pattern of Eocene or Oligocene age for these events (Table 4). Hence, these events are assigned an "Eocene or Oligocene" age.

Assigning ages to a stratigraphic section from a list of ordered events involves some degree of judgment by the worker. In this study, ages were assigned to cored sediments using the stratigraphic range of events within the same age. We used judgment when the range for an age became unreasonable by limiting ourselves to those events with higher reliability indices (greater than 0.61 ). Uncertainty of some boundaries resulted from overlap in placing these ages onto a stratigraphic section and is indicated by hachuring (Tables 1,2 ). We are not yet able satisfactorily to evaluate reworking of taxa. However, at Hole 595A we feel that enough mixing of taxa has occurred so that the Cretaceous/Tertiary boundary is crosshachured (Table 1). The age determinations of sediments cored at Sites 595 and 596 that follow are based primarily on the more reliable ichthyolith events, but are also supplemented by the presence of other ichthyolith taxa.

\section{Site 595}

Ichthyoliths suggest that the entire Cenozoic is contained in the upper 15-16 m (Cores 1-3) of Hole 595A. Throughout the sequence there is evidence of older forms mixed into younger assemblages, probably as a result of drilling disturbance. Samples from Core 1 and the top of Core 2 are Miocene or younger, based on the earliest occurrences of Elliptical with line across, Short rectangular with striations, and Circular with line across. The absence of Long ellipse and Narrow triangle ragged base and the presence of a single specimen of Long triangle stepped margin in Core 1 samples suggest that Pliocene and Quaternary sediments are either absent or at most $1.6 \mathrm{~m}$ thick. The presence of Elliptical with line across in a sample from Section 595A-2-1 suggests that the sample is not older than middle Miocene, and that the early Miocene is absent or thin.

Sections 595A-2-2 to -5 are Eocene-Oligocene. An irregular and conflicting pattern of earliest and latest occurrences in this part of Hole 595A makes a distinction between Oligocene and Eocene unreliable. However, the sample from Section 595A-2-2 appears to be Oligocene, on the basis of the earliest occurrences of Large with numerous lines, Small dendritic few radiating lines, and Rounded apex triangle, as well as the fact that it is below Miocene events, including the earliest occurrences of Small triangle long striations, Elliptical with line across, Circular with line across, and Short rectangular with striations.

Section 595A-3-2 is Paleocene, on the basis of the earliest occurrences of Triangle medium wing, Triangle with triangular projection, and Triangle radiating inline. The Paleocene/Eocene boundary is between Sections 595A-2-5, and 595A-3-2. The presence of Beveled triangle mid inline, Short triangle bowed inline, and Flexed triangle asymmetric in samples from Section 595A-3-1 suggests that this boundary most probably occurs between Cores 2 and 3. The presence of Cretaceous subtypes (Centrally striated triangle and Wide triangle projection) in the assemblage from Section 595A-3-2 suggests reworking and/or core disturbance.

Cores 4 to 9 are Mesozoic, judging by the presence of Wide triangle projection, Blunt triangle dendritic inline, Triangle long inline, Triangle square inline, and the earliest occurrences of Capped triangle and Small triangle keeled edges. The Cretaceous/Tertiary boundary is between Sections 595A-3-2 and 595A-4-1. A mixture of Cretaceous and Cenozoic forms in samples from Section 595A-3-3 does not allow a more precise placement of the 


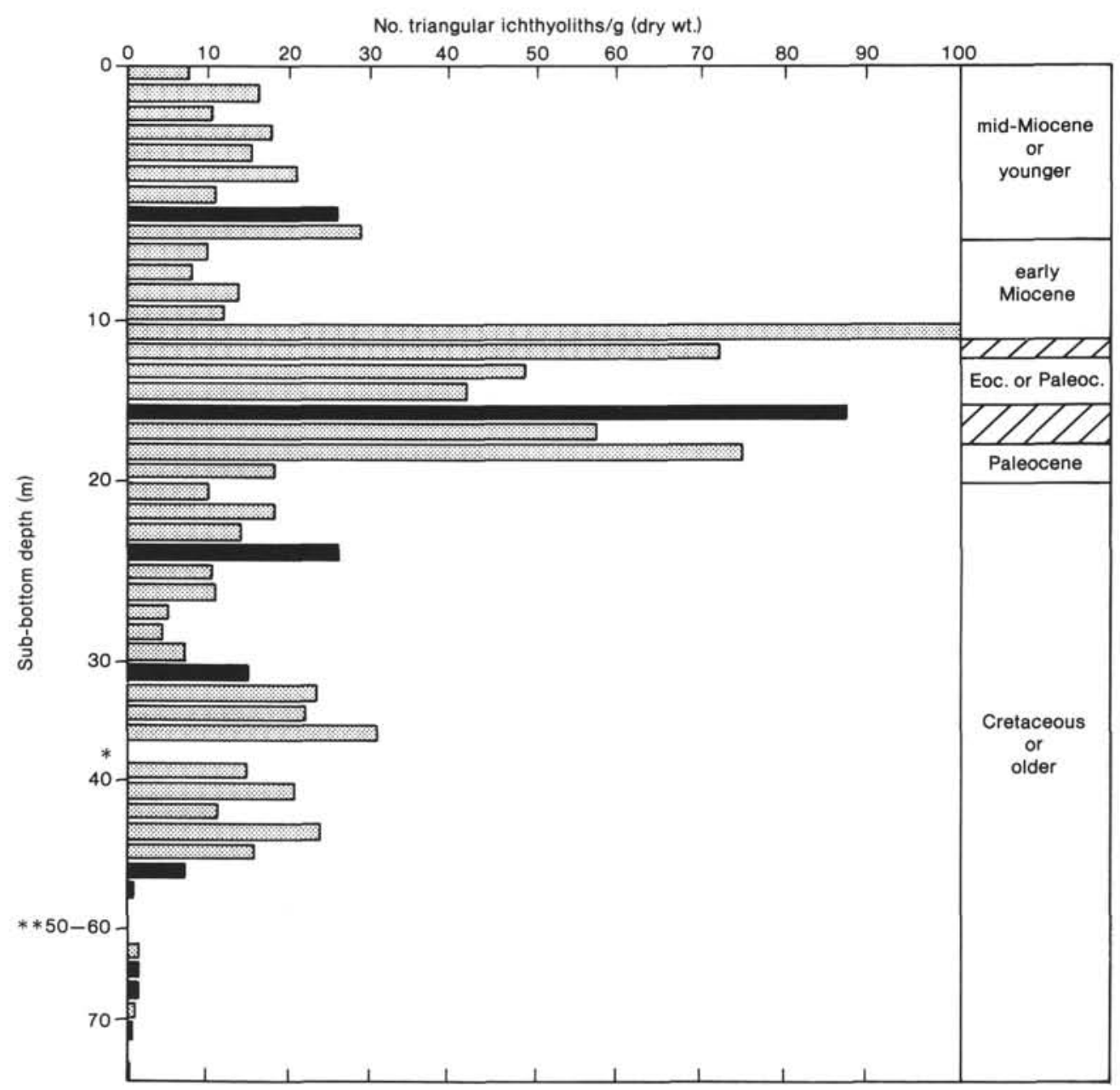

Figure 2. Concentration of ichthyoliths with depth at Site 596. Bars represent the concentrations of each sample. Depths are not evenly spaced, especially between 50 and $60 \mathrm{~m}$ (double asterisks), where poor recovery did not allow for sampling. Ages of samples, determined by ichthyoliths, are marked, with hachuring indicating uncertainty of boundaries. Black bars record concentrations of triangular ichthyoliths larger than $44 \mu \mathrm{m}$; these results are not comparable with the others, which record concentrations larger than $63 \mu \mathrm{m}$. Single asterisk indicates that dry weight not recorded and concentration not determined.

boundary. Mesozoic ichthyoliths have not been studied sufficiently to permit stratigraphic divisions.

\section{Site 596}

The Cenozoic is contained within the upper $20 \mathrm{~m}$ at Site 596. Samples from Core 596-1 to Section 596-2-4 are Miocene or younger, on the basis of the occurrence of Triangle sinuous inline, Stippled triangle, Circular with line across, and Small triangle long striations. The presence of Long ellipse, Narrow triangle ragged base, and Elliptical with line across in the upper $6 \mathrm{~m}$ suggests that Core 1 and Section 596-2-1 are middle Miocene or younger. The absence of these forms in the lower part of the Miocene section suggests an early Miocene age.

The Eocene-Oligocene/early Miocene boundary is within Core 2, between Sections 4 and 5. No distinction between Eocene and Oligocene can be made because the pattern of earliest and latest occurrences in the small samples examined is irregular and conflicting. The $\mathrm{Pa}-$ leocene/Eocene boundary falls between Sections 596-2-6 and 596-3-2.
Sections 2 and 3 of Core 3 are Paleocene on the basis of the earliest occurrences of Cenozoic taxa, Triangle with triangular projection, Triangle medium wing, and Triangle curved margin ends, and the absence of Cretaceous forms.

The Cretaceous/Tertiary boundary is within Core 3, between Sections 3 and 4. Section 596-3-4 and lower samples are Cretaceous or older on the basis of the latest occurrences of Triangle square inline and Wide triangle projection and the earliest occurrences of Triangle long inline and Triangle square inline. Taxa commonly found in the Cretaceous (Triangle square inline, Wide triangle projection, Triangle long inline, and Blunt triangle dendritic inline) are present throughout Section 596-6-5. Radiolarians in a sample from Section 5 suggest an Albian or Late Cretaceous age. The core-catcher samples from Cores 6 and 7 and from Section 1 of Core 9 contain bone fragments, but essentially no identifiable ichthyoliths.

Hole 596A was cored in order to recover the oldest sediments above basement. Mesozoic ichthyoliths have 


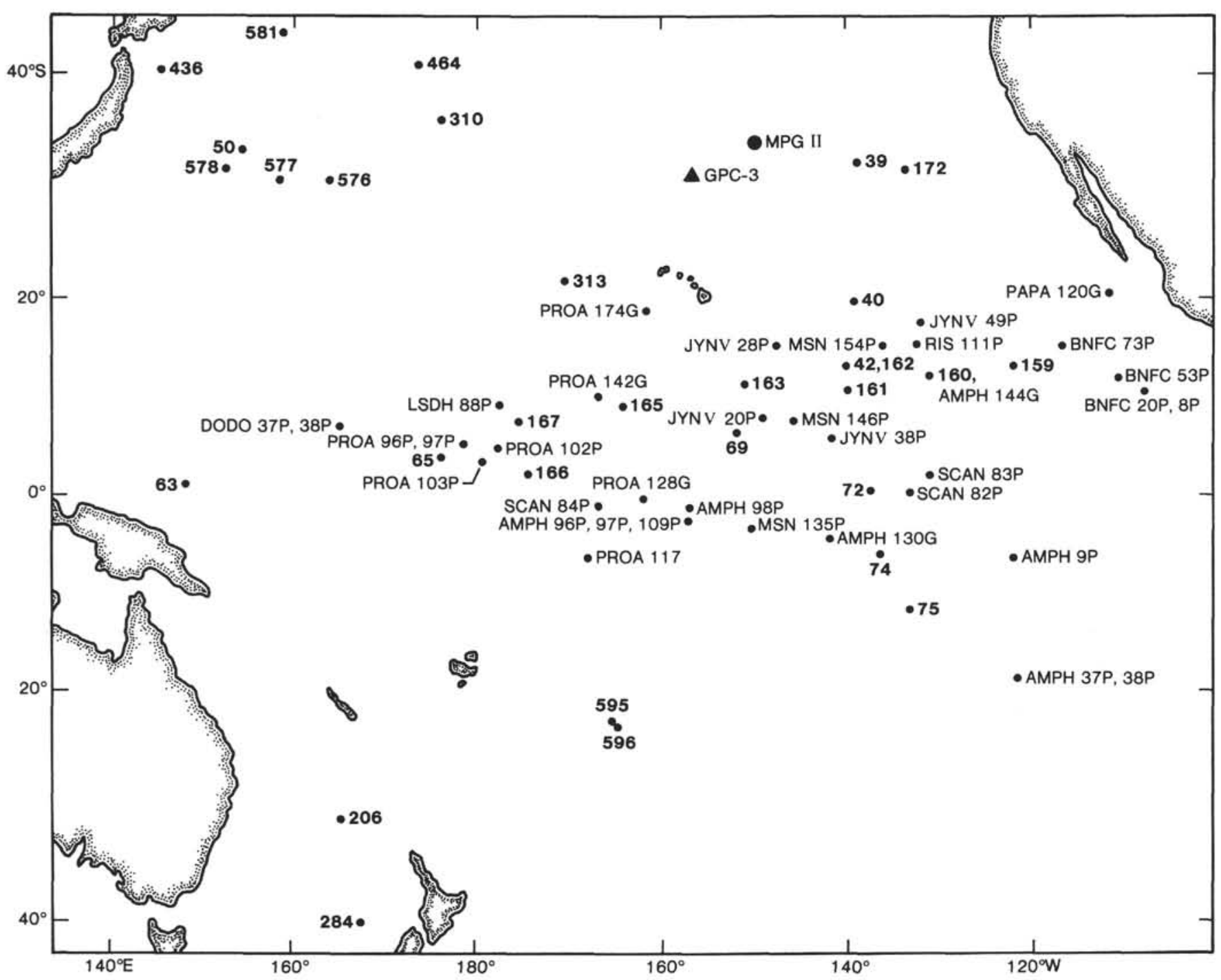

Figure 3. Sites from which samples were used in this study. DSDP sites in bold type. Pelagic clay sequences from DSDP Sites 595 and 596 are the main objects of this study. Sequences from DSDP Sites 576, 578 and 581, GPC-3, and MPG II are pelagic clay, and provided the basis for a synthesis of ichthyolith stratigraphy in the North Pacific (Doyle and Riedel, 1985b). Most of the other sites contain microfossils additional to ichthyoliths, providing independent means of establishing ichthyolith ranges.

Table 3. Reliability factors and multipliers used in this study.

\begin{tabular}{|c|c|c|c|c|c|c|c|}
\hline \multirow[b]{2}{*}{ Reliability factor } & \multicolumn{7}{|c|}{ Multiplier } \\
\hline & 0 & 0.05 & 0.10 & 0.25 & 0.50 & 0.75 & 0.95 \\
\hline $\begin{array}{l}\text { 1. Constancy of taxa } \\
\text { presence in } \\
\text { samples near } \\
\text { event }\end{array}$ & & $\begin{array}{c}\text { Not present in } \\
4 \text { samples } \\
\text { near event }\end{array}$ & $\begin{array}{l}\text { Present in } \\
1 \text { of } 4 \\
\text { samples }\end{array}$ & $\begin{array}{l}\text { Present in } \\
2 \text { of } 4 \\
\text { samples }\end{array}$ & & $\begin{array}{l}\text { Present in } 3 \\
\text { of } 4 \\
\text { samples }\end{array}$ & $\begin{array}{c}\text { Present in all } 4 \\
\text { samples } \\
\text { near event }\end{array}$ \\
\hline $\begin{array}{l}\text { 2. Strength of event } \\
\text { signal (number of } \\
\text { taxa at event) }\end{array}$ & & $\begin{array}{l}1 \text { broken } \\
\text { specimen }\end{array}$ & 1 & & 2 to 5 & & $>5$ \\
\hline $\begin{array}{l}\text { 3. Ease of recognition } \\
\text { of } \operatorname{taxa}\end{array}$ & & & Difficult & & Moderate & & Easy \\
\hline $\begin{array}{l}\text { 4. Number of samples } \\
\text { above or below } \\
\text { event }\end{array}$ & 0 & & 1 & 2 & 3 & 4 & $>4$ \\
\hline $\begin{array}{l}\text { 5. Evolutionary type } \\
\text { of event }\end{array}$ & & & & & & Morphotypic & \\
\hline
\end{tabular}


Table 4. Most likely order of events that have reliability indices in the top third (reliability index $>0.40$ ) and are common to both Sites 595 and 596 .

\begin{tabular}{|c|c|c|c|c|c|c|c|c|c|c|c|}
\hline \multirow[b]{2}{*}{$\begin{array}{l}\text { Event } \\
\text { type }\end{array}$} & \multirow[b]{2}{*}{ Subtype } & \multicolumn{3}{|c|}{ Site 596} & \multicolumn{3}{|c|}{ Hole 595A } & \multirow{2}{*}{$\begin{array}{l}\text { Avg. } \\
\text { rel. } \\
\text { index }\end{array}$} & \multirow{2}{*}{$\begin{array}{l}\text { Composite of dated } \\
\text { samples, Pacific } \\
\text { (nanno. zones, } \\
\text { Okada and } \\
\text { Bukry, 1980) }\end{array}$} & \multirow{2}{*}{$\begin{array}{l}\text { "Probable ages" } \\
\text { North Pacific } \\
\text { (Doyle and } \\
\text { Riedel, 1985b) }\end{array}$} & \multirow[b]{2}{*}{ Age } \\
\hline & & Upper & (m) & $\begin{array}{l}\text { Rel. } \\
\text { index }\end{array}$ & \multicolumn{2}{|c|}{ (m) } & $\begin{array}{l}\text { Rel. } \\
\text { index }\end{array}$ & & & & \\
\hline MT & Circular with pores & 3.88 & 4.02 & 0.42 & 6.44 & 9.08 & 0.44 & 0.43 & & & \multirow{9}{*}{$\begin{array}{l}\text { Miocene } \\
\text { or younger }\end{array}$} \\
\hline MB & Elliptical with line across & 6.09 & 6.28 & 0.76 & 3.40 & 4.90 & 0.70 & 0.73 & $\mathrm{CN} 7$ & Miocene & \\
\hline MB & Short rectangular with striations & 6.28 & 7.59 & 0.44 & 3.40 & 4.90 & 0.70 & 0.57 & CN5 & Miocene & \\
\hline MT & Fibrous triangle convex margins & 7.74 & 9.10 & 0.44 & 4.94 & 6.44 & 0.58 & 0.51 & CP15-12 & \multirow{6}{*}{$\begin{array}{l}\text { Miocene } \\
\text { Miocene } \\
\text { Miocene } \\
\text { Miocene } \\
\text { Miocene }\end{array}$} & \\
\hline MT & Triangle medium wing & 9.13 & 10.63 & 0.66 & 3.44 & 4.94 & 0.44 & 0.50 & CN5 & & \\
\hline MT & Triangle with parallel inline & 9.13 & 10.63 & 0.44 & 6.44 & 9.08 & 0.44 & 0.44 & CN15 & & \\
\hline MT & Triangle pointed margin ends & 10.63 & 11.40 & 0.45 & 4.94 & 6.44 & 0.58 & 0.52 & $\mathrm{CN} 2$ & & \\
\hline MT & Triangle short wing & 10.63 & 11.40 & 0.51 & 6.44 & 9.08 & 0.51 & 0.51 & CN8 & & \\
\hline MB & Circular with line across & 11.34 & 12.09 & 0.66 & 3.40 & 4.90 & 0.80 & 0.73 & CN7 & & \\
\hline MB & Small triangle long striations & 11.34 & 12.09 & 0.62 & 3.40 & 4.90 & 0.54 & 0.58 & $\mathrm{CN1}$ & Mio./Oligo. & \multirow{2}{*}{ Mio./Oligo. } \\
\hline MB & Rectangular saw-toothed & 11.34 & 12.09 & 0.70 & 4.90 & 6.40 & 0.66 & 0.68 & $\mathrm{CN} 2$ & Mio./Oligo. & \\
\hline MB & Large with numerous lines & 11.34 & 12.09 & 0.86 & 4.90 & 6.40 & 0.80 & 0.83 & CP17 & Oligocene & \multirow{7}{*}{ Oligocene } \\
\hline MT & Triangle curved margin ends & 11.40 & 12.11 & 0.58 & 6.44 & 9.08 & 0.45 & 0.52 & & & \\
\hline MB & Triangle with parallel inline & 11.34 & 12.09 & 0.51 & 9.02 & 11.80 & 0.44 & 0.48 & CP16 & Oligocene & \\
\hline MB & Small dendritic many radiating lines & 10.59 & 11.34 & 0.58 & 9.02 & 11.80 & 0.54 & 0.56 & CP15 & Oligocene & \\
\hline MB & Circular with pores & 9.09 & 10.59 & 0.44 & 9.02 & 11.80 & 0.44 & 0.44 & & & \\
\hline MB & Pointed triangle long margins & 11.34 & 12.09 & 0.86 & 11.80 & 12.70 & 0.70 & 0.79 & CP14-11 & Oligocene & \\
\hline MB & Curved triangle pointed margin & 13.59 & 14.87 & 0.61 & 3.40 & 4.90 & 0.48 & 0.55 & CP17 & Oligocene & \\
\hline MB & Rectangular irregularly saw-toothed & 13.59 & 14.87 & 0.70 & 11.80 & 12.70 & 0.70 & 0.70 & CP14 & \multirow{6}{*}{ Paleocene } & \multirow{6}{*}{$\begin{array}{l}\text { Eocene or } \\
\text { Oligocene }\end{array}$} \\
\hline MB & Tanged triangle & 12.09 & 13.59 & 0.54 & 12.70 & 12.75 & 0.54 & 0.54 & CP11 & & \\
\hline $\mathrm{MB}$ & Flexed triangle shallow inbase & 14.87 & 16.18 & 0.70 & 12.75 & 14.20 & 0.66 & 0.68 & CP12 & & \\
\hline MB & Narrow triangle straight inbase & 13.59 & 14.87 & 0.61 & 12.75 & 14.20 & 0.44 & 0.53 & CP17 & & \\
\hline MB & Rounded apex triangle & 14.87 & 16.18 & 0.66 & 4.90 & 6.40 & 0.61 & 0.64 & CP16 & & \\
\hline MB & Narrow triangle cross-hachured & 16.18 & 17.68 & 0.44 & 11.80 & 12.70 & 0.70 & 0.57 & CP12 & & \\
\hline MB & Triangle medium wing & 16.18 & 17.68 & 0.76 & 14.20 & 15.70 & 0.70 & 0.73 & $\mathrm{CP} 2$ & Paleocene & \multirow{5}{*}{ Paleocene } \\
\hline $\mathrm{MB}$ & Triangle with triangular projection & 17.68 & 19.18 & 0.76 & 14.20 & 15.70 & 0.70 & 0.73 & $\mathrm{CP} 2$ & Paleocene & \\
\hline MB & Triangle radiating inline & 17.68 & 19.18 & 0.45 & 14.20 & 15.70 & 0.76 & 0.61 & CP4-3 & Paleocene & \\
\hline MT & Triangle sigmoid rough & 17.71 & 19.21 & 0.62 & 14.25 & 15.72 & 0.67 & 0.65 & & & \\
\hline MB & Triangle short wing & 16.18 & 17.68 & 0.44 & 15.75 & 22.40 & 0.44 & 0.44 & $\mathrm{CP} 12-2$ & Paleocene & \\
\hline MT & Triangle square inline & 19.21 & 20.71 & 0.66 & 12.77 & 14.25 & 0.50 & 0.58 & K & Cretaceous & \multirow{8}{*}{$\begin{array}{l}\text { Cretaceous } \\
\text { or older }\end{array}$} \\
\hline MT & Wide triangle projection & 20.71 & 22.21 & 0.61 & 25.07 & 26.59 & 0.58 & 0.60 & $\mathbf{K}$ & Cretaceous & \\
\hline MB & Capped triangle & 43.43 & 44.90 & 0.62 & 32.22 & 37.60 & 0.43 & 0.52 & & & \\
\hline MB & Blunt triangle dendritic inline & 46.68 & 49.25 & 0.51 & 37.60 & 54.90 & 0.62 & 0.57 & & & \\
\hline MB & Small triangle keeled edges & 46.68 & 49.25 & 0.70 & 37.60 & 54.90 & 0.59 & 0.65 & & & \\
\hline MB & Triangle long inline & 46.68 & 49.25 & 0.61 & 37.60 & 54.90 & 0.45 & 0.53 & $\mathrm{~K}^{*}$ & Cretaceous & \\
\hline $\mathrm{MB}$ & Triangle square inline & 46.68 & 49.25 & 0.44 & 54.90 & 57.48 & 0.51 & 0.47 & $\mathrm{~K}^{*}$ & Cretaceous & \\
\hline MB & Triangle sigmoid rough & 67.81 & 69.31 & 0.47 & 23.90 & 23.94 & 0.42 & 0.45 & & & \\
\hline
\end{tabular}

Note: MT indicates a morphotypic top (latest occurrence). MB indicates morphotypic base (earliest occurrence). Upper and lower depth ranges for each event at each site give the depth of samples bracketing each event. An asterisk denotes that the earliest occurrence in dated samples corresponds to the lower limits of sampling.

not been studied sufficiently to allow us reliably to discriminate Cretaceous from Jurassic sediments, and, moreover, ichthyoliths are rare throughout the core.

Ichthyoliths are common in Hole 596B and indicate that the core is Cretaceous. This hole was cored to recover the missed interval between 24.7 and $34.3 \mathrm{~m}$ in Hole 596. Comparison of ichthyolith assemblages in this core with that of Hole 596 suggests that drilling depths are approximately correct.

\section{SYSTEMATIC SECTION}

Two previously described subtypes which first appear in the Mesozoic are emended below. Thirteen new subtypes which first appear in Cretaceous or older strata are described. The upper limits of some of these new Mesozoic forms are not yet determined. The procedure for describing and naming ichthyoliths involves use of a string of letters and numbers corresponding to objectively defined characters of the image as seen in a transmitted-light microscope. These name-descriptions can be decoded in full by reference to Doyle and Riedel (1979a, 1980, 1985b), Gottfried et al. (1984), and Tway et al. (1985). Distinctive features necessary to distinguish each subtype from described and undescribed forms are pointed out in the text. The coded descriptions are frequently long, and therefore colloquial names are coined to act as their surrogates. In order to differentiate the newly described subtypes, the following changes to the descriptive system are required.
1. For $b$, modify Prominent features within the outline to read Distinguishing prominent features within the outline

2. Under $b$, add the characterstate:

10. two or more prominent lines intersecting to form a crosslike pattern

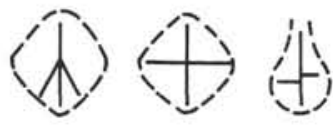

3. Under Type $a 3,5 / b 8$, add the character:

f. Internal features

0 . none

1. single median line

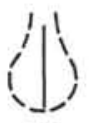

4. Under the new Type $a 3,5 / b 10$, add the characters:

c. Shape

1. kite-shaped, the longer sides of which are concave

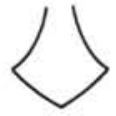

2. subcircular to equant (maximum length approximately equals maximum width)<smiles>C1CCCCC1</smiles>

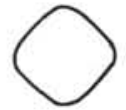

d. Orientation and pattern of lines 
1. oriented perpendicularly $\left(80^{\circ}\right.$ to $\left.100^{\circ}\right)$ with offset lines

2. oriented perpendicularly $\left(80^{\circ}\right.$ to $\left.100^{\circ}\right)$ but lines not offset

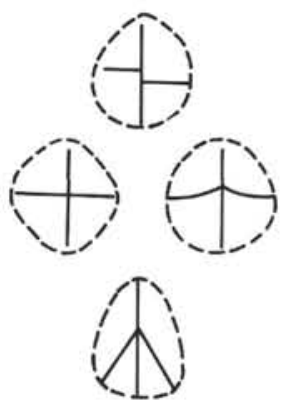

5. Under Type $a 9 / b 1,5$, add the character-state:

g. 6. longitudinal, parallel to subparallel lines

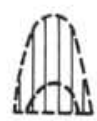

\section{TAXONOMIC REVISIONS}

subtype a4/b1, 2/c2/d1, 4/e2/f2 +3/g1 + 2/h1 Doyle et al., 1974; emend. herein

Plain and lined lanceolate

$a 4 / b 1 / c 2 / d 1 / e 0 / f 1,(2+3) / g 1+2$ (Plain lanceolate), Doyle et al., 1974, pl. $2 \mathrm{~F}$, figs. $1-4$, p. 844 .

$a 4 / b 1,2 / c 2 / d 1,2,3 / e 2 / f 1,(2+3) / g 1+2 / h 1$, emend. Doyle et al., 1978 , pl. 1 , figs. 13,14 , p. 748 .

$a 4 / b 1,2 / c 2 / d 1,2,3 / e 2 / f 1,(2+3) / g 1+2 / h 1$, Doyle and Riedel, 1979 b, pl. 3 , fig. 11 ; pl. 5 , fig. $31 ;$ pl. 8 , figs. 4,5 , p. 341.

$a 4 / b 1,2 / c 2 / d 1,2,4 / e 2 / f 2+3 / g 1+2 / h 1$, emend. Doyle and Riedel, 1979a, pl. 2, fig. 2, p. 47.

Remarks. We remove the character state $d 2$ to exclude lanceolate forms with a single longitudinal line, now included in Lanceolate median line (new subtype). As such, Plain and lined lanceolate includes forms with no lines or more than one longitudinal line $(d l, 4)$. Figures of specimens referred to in the synonymy above fall within this revised concept of Plain and lined lanceolate.

subtype $\mathrm{a} 9 / \mathrm{b} 1 / \mathrm{cl} / \mathrm{d} 1 / \mathrm{e} 1 / \mathrm{f} 4+8+15 / \mathrm{g} 1 / \mathrm{h} 5 / \mathrm{i} 2,6 / \mathrm{j} 2,3 / \mathrm{k} 3 / \mathrm{m} 0.40$

$0.60 / \mathrm{n} 1.40-2.30 / \mathrm{p} 0 / \mathrm{q} 2,6 / \mathrm{r} 1 / \mathrm{s} 1,3 / \mathrm{t1} / \mathrm{z0}$ Ramsey et al., 1976; emend. herein

Triangle bowed inline

(Plate 1, Figs. 1a-c)

$a 9 / b 1 / c 1 / d 1 / e l / f 1,4 / g 1 / h 5 / i 2 / j 2 / k 3,9 / 10.4-0.6 / \mathrm{m} 1.4-2.4 / \mathrm{n} 2,6 /$ ol/p1, 3/q4, Ramsey et al., 1976, pl. 3, figs. 6-10, p. 130.

$a 9 / b 1 / c l / d 1 / e l / f 1,4 / g 1 / h 5 / i 2 / j 2 / k 3,9 / 10.4-0.6 / \mathrm{m} 1.4-2.8 / \mathrm{n} 2,6 /$ o1/p1, 3/q4, Doyle and Riedel, 1979b, pl. 3, fig. 31, p. 343.

$a 9 / b 1 / c l / d 1 / e l / f 4 / g 1 / h 5 / i 2,6 / j 2,3 / \mathrm{k} 3 / \mathrm{m0} 0.40-0.60 / n 1.40-2.30 / p 0 /$

$q 2,6 / r 1 / s 1,3 / t 1$, emend. Doyle and Riedel, 1979a, pl. 6, figs. 16, 17 , p. 115.

Remarks. We add the character states $f 8+15$ to include longitudinal striations radiating from inline. Original specimens exhibit this feature (Ramsey et al., 1979, pl. 3, figs. 6-10).

subtype a9/b1/c1/d1/e1/f10 + $(12,13)+14 / g 1 / h 3,4,5 / \mathbf{i} 2 / \mathrm{j} 2 / \mathrm{k} 0,11 /$ m0/n1.10-1.60/p1.10-1.70/q2, 3, 4, 9/r1/s1/t1 + a8/b1, 5/c1/d1, 2/e88-93/f29-40/g1, 2/h0 Doyle et al., 1978; emend. herein Centrally striated triangle

(Plate 1, Figs. 2a-c)

Fish tooth type E-1, Helms and Riedel, 1971, pl. 2, fig. 18, p. 1713. $a 9 / b 1 / c 1 / d 1 / e l / f 10+(12,13)+14 / g 1 / h 4, \quad 5 / i 2 / j 2 / k 11 / 10 / m 1.1-$ $1.6 / n 3,4,9 / o 1 / p 1 / q 1+a 8 / b 1,5 / c 1 / d 1 / e 88-93 / f 29-40$, Doyle et al., 1978, pl. 2, figs. 19-21, p. 749.

$a 9 / b 1 / c 1 / d 1 / e 1 / f 10+(12,13)+14 / g 1 / h 4,5 / i 2 / j 2 / k 11 / 10 / m 1.1-1.9 /$ $n 3,4,9 / o 1 / p 1 / q 1+a 8 / b 1,5 / c 1 / d 2 / e 88-93 / f 29-40$, Doyle and Riedel, 1979b, pl. 9, figs. 4-6, p. 348.

$\mathrm{a} 9 / \mathrm{bl} / \mathrm{cl} / \mathrm{dl} / \mathrm{el} / \mathrm{flO}+(12,13)+14 / \mathrm{gl} / \mathrm{h} 3,4,5 / \mathrm{i} 2 / \mathrm{j} 2 / \mathrm{k0}, 11 / \mathrm{mo} /$ n1.10-1.60/p1.10-1.70/q2, 3, 4, 9/rl/sl/t1 + a8/b1, 5/cl/d2/ e88-93/f29-40, emend. Doyle and Riedel, 1979a, pl. 9, figs. 5-7.

Remarks. Forms having a single prominent flexure above the base, with the antapical flexure edge curved, are judged sufficiently similar to Centrally striated triangle to be included within that subtype. Of the forms illustrated on Plate 1, the specimens in Figs. $2 b, c$ possess margins with pronounced angular flexures (width of flexure $>20 \%$ width of tooth) and are described by the characters associated with Type $a 8 / b 1,5$. Figure $2 \mathrm{a}$ illustrates a specimen in which the angular modification of the margin is shallower. This form is described by the characters listed under Type $a 9 / b 1$.

\section{NEW TAXA}

subtype a3, 4/b2/c2, 3/d2/e2/f2 + 3/g1 + (2, 8)/h1, 3, 4 New subtype

Lanceolate median line

(Plate 1, Figs. 3a-e)

$a 4 / b 1,2 / c 2 / d 1,2,3 / e 2 / f 1,(2+3) / g 1+2 / h 1$ (Plain and lined lanceolate), emend. Doyle et al., 1978, pl. 1, figs. 12, 14.

$a 4 / b 1,2 / c 2 / d 1,2,4 / e 2 / f 2+3 / g 1+2 / h 1$ (Plain and lined lanceolate), emend. Doyle and Riedel, 1979a, pl. 2, fig. 3.

Characters. Lanceolate to polygonal form with single, longitudinal median line. Height of acute prominence is greater than length of base, but less than twice its length. Narrow differentiated area is present on all margins. Margins on long sides of acute prominence are smooth and continuous. Margins of short sides are broken. Sides of acute prominence are convex, slightly concave, or sigmoid. Overall length $170-310 \mu \mathrm{m}$, maximum width $110-170 \mu \mathrm{m}$.

Distinction from similar forms. Other undescribed forms exhibit a single longitudinal median line (Pl. 1, Fig. 4), but differ in that height of acute prominence is equal to or less than length of base, and that sides of acute prominence are pronouncedly concave. Lanceolate median line does not have four distinct sides, as does Kite-shaped longitudinal line (Doyle et al., 1974, pl. 2c, figs. 1, 2). Plain and lined lanceolate (Doyle and Riedel, 1979a, pl. 2, figs. 2, 3) differs in that the margins opposite acute prominence are smooth instead of appearing broken.

Occurrence. Earliest occurrence in Cretaceous or older strata of Holes 595A, 596, 596B (Table 5).

Remarks. The concept of Plain and lined lanceolate is revised herein under Taxonomic Revisions. Figures of specimens referred to in the synonymy above are included in Lanceolate median line.

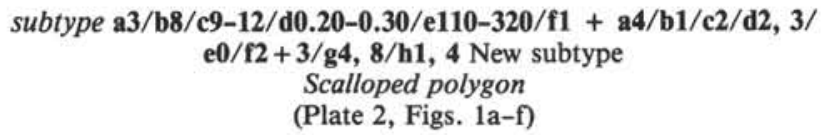

Characters. External shape varies from polygonal to lanceolate. Polygonal form (Pl. 2, Figs. 1a, b, d-f) has a lanceolate-shaped figure of 9 to 12 sides within the outline. Lengths of sides vary greatly. Single median line lies within polygonal pattern. Lanceolate forms (PI. 2, Fig. 1c) have a single medial longitudinal line with a differentiated area along margin edges. Sides opposite acute prominence irregularly undulating or broken, with a distinctive scalloped border. Sides of acute prominence are straight or convex. Maximum dimensions 110 $320 \mu \mathrm{m}$.

Distinction from similar forms. Undescribed forms similar to Scalloped polygon have fewer than 9 sides (Pl. 2, Fig. 2). In similar described forms, Pointed and skirted (Doyle et al., 1978, pl. 1, fig. 9; Doyle and Riedel, 1979a, pl. 1, fig. 17) does not have an extensive, well-defined scalloped border opposite the acute prominence. Prominence with wye-line (Doyle et al., 1978, pl. 1, figs. 1-4) has longer acute prominence, and so differs from Scalloped polygon.

Occurrence. Earliest occurrence in Cretaceous or older strata from Holes 595A and 596 (Table 5).

\section{subtype $\mathbf{a} 3 / \mathrm{b} 10 / \mathrm{c1} / \mathrm{d} 1,2$ New subtype Crossed kite \\ (Plate 2, Figs. 3a-f)}

Characters. Kite-shaped form with prominent lines that intersect to form a crosslike pattern. Lines lie perpendicular to each other and are offset. Overall length $210-280 \mu \mathrm{m}$, maximum width $120-230 \mu \mathrm{m}$.

Distinction from similar forms. Whereas other forms have the distinctive crosslike pattern, they are not kite-shaped.

Occurrence. Earliest occurrence in Cretaceous or older strata from Holes 595A and 596 (Table 5). 
E. C. WINFREY, P. S. DOYLE, W. R. RIEDEL

Table 5. Stratigraphic distribution of new ichthyolith subtypes in selected samples at Sites 595 and 596.

\begin{tabular}{|c|c|c|c|c|c|c|c|c|c|c|c|c|c|c|c|c|}
\hline Age & $\begin{array}{c}\text { Sample } \\
\text { (interval in cm) }\end{array}$ & $\begin{array}{l}\text { Depth }(\mathrm{m}) \\
\text { to top of } \\
\text { sample }\end{array}$ & 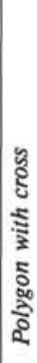 & 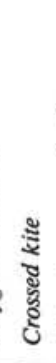 & 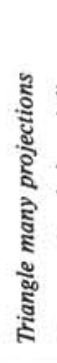 & 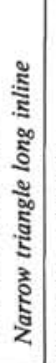 & 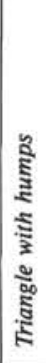 & 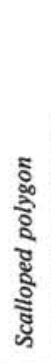 & 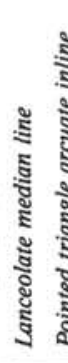 & 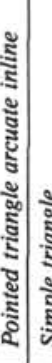 & 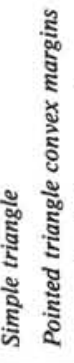 & 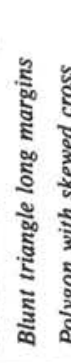 & 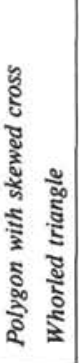 & $\begin{array}{c}\text { Total } \\
\text { no. } \\
\text { triangular } \\
\text { forms }^{\mathrm{a}}\end{array}$ & $\begin{array}{l}\text { Dry wt. } \\
\text { sample } \\
\text { (g) }\end{array}$ & $\begin{array}{c}\text { No. } \\
\text { triangular } \\
\text { forms } / g^{a}\end{array}$ \\
\hline \multirow[t]{9}{*}{ Paleocene } & Hole 595A & & & & & & & & & & & & & & & \\
\hline & $3-2,50-55$ & 14.20 & & & & & 1 & & & & & & 1 & 947 & 10.66 & 88.84 \\
\hline & $3-3,50-52$ & 15.70 & & 1 & & & 1 & & & & & & & 141 & 11.82 & 11.93 \\
\hline & $3-3,55-57$ & 15.75 & & 1 & & & & & & & & & & 65 & 5.36 & 12.13 \\
\hline & $4-1,60-64$ & 22.40 & & & & & & & & & & & & 35 & 10.11 & 3.46 \\
\hline & $4-2,60-64$ & 23.90 & 1 & 1 & & & & 1 & & & & 1 & & 199 & 16.56 & 12.02 \\
\hline & $4-2,64-66$ & 23.94 & & & & & & & & & & & & 46 & 6.76 & 6.80 \\
\hline & $4-3,24-29$ & 25.04 & 1 & & & & & & & & & 1 & & 101 & 9.55 & 10.58 \\
\hline & $4-4,24-29$ & 26.54 & 3 & & & & & 1 & 2 & & 2 & & 1 & 149 & 10.28 & 14.49 \\
\hline \multirow{7}{*}{$\begin{array}{l}\text { Cretaceous } \\
\text { or older }\end{array}$} & $4-6,22-27$ & 29.52 & 2 & 1 & & & & & & & & 92 & 2 & 152 & 11.87 & 12.81 \\
\hline & $5-1,82-85$ & 32.22 & & & 3 & & & & 1 & & & & & 109 & 8.21 & 13.28 \\
\hline & $5-7,30-37$ & 37.60 & 1 & & & 15 & & & 1 & 16 & $\begin{array}{ll}6 & 1\end{array}$ & & & 163 & 22.48 & 7.25 \\
\hline & $8-3,130-136$ & 54.90 & 3 & & & & & & & & & & & 32 & 30.96 & 1.03 \\
\hline & $8, \mathrm{CC}(68-73)$ & 57.48 & & & & & & & & & 1 & & & 60 & 13.92 & 4.31 \\
\hline & $9-1,77-82$ & 60.97 & & & & & & & & & & & & 6 & 10.49 & 0.57 \\
\hline & Site 596 & & & & & & & & & & & & & & & \\
\hline \multirow[t]{4}{*}{ Paleocene } & $3-3,108-111$ & 19.18 & & & & & & & & & 1 & & & 114 & 6.53 & 17.46 \\
\hline & $3-4,108-111$ & 20.68 & & & & & & & & & & & 3 & 44 & 4.59 & 9.59 \\
\hline & $3-5,108-111$ & 22.18 & & & & & & & & & & & 1 & 88 & 5.01 & 17.56 \\
\hline & $3-6,108-111$ & 23.68 & & & & & & & & & & & & 79 & 5.83 & 13.55 \\
\hline \multirow[t]{15}{*}{ Cretaceous } & $3, \mathrm{CC}$ & 24.63 & & & & & & & & 1 & & & & •177 & 7.05 & 25.11 \\
\hline & B1-1, 79-82 & 25.49 & & & & & & & & & & & & 61 & 6.29 & 9.70 \\
\hline & B1-2, 79-82 & 26.99 & & & & & & & 11 & 1 & & & & 58 & 5.53 & 10.49 \\
\hline & B1-3, 79-82 & 28.49 & & & & & & & & 1 & & & & 36 & 7.39 & 4.87 \\
\hline & B1-3, $75-80$ & 28.45 & & & & & & & & & & & & 105 & 27.77 & 3.78 \\
\hline & B1- $4,79-82$ & 29.99 & & & & & & & & 1 & & & 1 & 40 & 5.82 & 6.87 \\
\hline & B1-5, 79-82 & 31.49 & & & & & & & & & & & & * 84 & 5.81 & *14.46 \\
\hline & $\mathrm{B} 1, \mathrm{CC}$ & 34.11 & & & & & & & & 1 & & 1 & & 157 & 6.94 & 22.62 \\
\hline & $5-2,81-84$ & 36.61 & & & & & & & & & 3 & & & 128 & 5.96 & 21.48 \\
\hline & $5-3,81-84$ & 38.11 & & & & 1 & 1 & 1 & & & 1 & & & 183 & 6.15 & 29.76 \\
\hline & $5-4,32-34$ & 39.12 & & & & & & & & & & & & * 1 & b & b \\
\hline & $5-4,81-84$ & 39.61 & 1 & & 2 & & & 1 & 1 & & & & & 116 & 8.17 & 14.20 \\
\hline & $5, \mathrm{CC}$ & 40.60 & & & 2 & 3 & & & 2 & & ? & & & 91 & 4.57 & 19.91 \\
\hline & $6-1,85-88$ & 40.65 & & & & & & & & & & 1 & & 65 & 6.10 & 10.66 \\
\hline & $6-3,63-67$ & 43.43 & & & 1 & & 1 & 1 & 1 & 12 & 2 & & & 211 & 9.18 & 22.98 \\
\hline \multirow{4}{*}{$\left.\begin{array}{c}\text { Late } \\
\text { Cretaceous } \\
\text { or Albian \# }\end{array}\right\}$} & $6-4,60-66$ & 44.90 & 2 & 2 & 3 & 14 & 1 & 1 & 21 & 13 & $\begin{array}{ll}3 & 1\end{array}$ & & & 288 & 18.87 & 15.26 \\
\hline & $6-5,88-91$ & 46.68 & & & & & & & & & & & & $\cdot 73$ & 10.96 & * 6.66 \\
\hline & $6, \mathrm{CC}(22-24)$ & 49.25 & & & & & & & & & & & & 3 & 14.66 & 0.20 \\
\hline & $7, \mathrm{CC}$ & 49.49 & & & & & & & & & & & & 0 & 12.56 & 0.00 \\
\hline \multirow{8}{*}{$\begin{array}{l}\text { Cretaceous } \\
\text { or older }\end{array}$} & $9-1,42-46$ & 69.02 & & & & & & & & & & & & 0 & b & 0.00 \\
\hline & A $1-1,70-78$ & 67.70 & 3 & & & & & & & & & & & 23 & 21.65 & 1.06 \\
\hline & A1-1, 81-84 & 67.81 & 1 & & & & & & & & & & & - 4 & 4.20 & $* 0.95$ \\
\hline & A $1-2,81-84$ & 69.31 & & & & & & & & & & & & - 6 & 5.66 & $* 1.06$ \\
\hline & A $1-2,92-98$ & 69.42 & & & & & & & & & & & & 17 & 19.25 & 0.88 \\
\hline & A1-3, 81-84 & 70.81 & & & & & & & & & & & & 2 & 5.79 & 0.35 \\
\hline & A1-3, 95-101 & 70.95 & & & & & & & & & & & & 3 & 26.56 & 0.11 \\
\hline & A $1-4,81-84$ & 72.31 & & & & & & & & & & & & - 5 & 9.94 & $* 0.50$ \\
\hline
\end{tabular}

Note: Upper limits of ranges are not determined. Ages are based on ichthyoliths except as noted by \#, where sample is dated by radiolarians. Cross-hachuring indicates mixing of taxa. A or B before sample number indicates samples from Holes 596A or 596B, respectively. ${ }^{a}$ Asterisks indicate shipboard samples in which the slides contain ichthyoliths larger than $44 \mu \mathrm{m}$.

${ }^{b}$ Dry weight not recorded; concentration cannot be determined.

\section{subtype a3, 5/b10/c2/d2 New subtype Polygon with cross (Plate 3, Figs. 1a-g)}

Characters. Subcircular to equant polygon with two lines oriented and intersecting at approximately right angles to form crosslike pattern. Maximum dimension $80-220 \mu \mathrm{m}$.
Distinction from similar forms. Polygonal form distinguished from undescribed polygons (Pl. 3, Fig. 5) by crosslike pattern of lines. Polygon with skewed cross (described below) has lines oriented and intersecting at oblique/acute angles.

Occurrence. Earliest occurrence in Cretaceous or older strata from Holes 595A, 596, and 596A (Table 5). 
subtype $\mathrm{a} 3, \mathbf{5} / \mathrm{b} 10 / \mathrm{c2} / \mathrm{d} 3$ New subtype

Polygon with skewed cross

(Plate 3, Figs. 2a-e)

Undescribed Paleocene or Cretaceous specimen, southeast Atlantic, Doyle et al., 1978, pl. 4, fig. 6 (specimen on right).

Characters. Subcircular to equant polygon with a crosslike pattern that lies internal to outline. Shorter lines oriented and intersecting at oblique/acute angles to the longer line. Maximum dimension 110$170 \mu \mathrm{m}$.

Distinction from similar forms. Polygonal form distinguished from undescribed polygons (Pl. 3, Fig. 5) by crossed pattern of lines. The obliquely/acutely crossed lines that lie within the polygonal outline distinguish this form from Polygon with cross (described above) which has lines oriented at right angles to each other.

Occurrence. Earliest occurrence in Cretaceous or older strata of Holes 595A, 596, and 596B (Table 5).

\section{subtype a9/b1/g1/d1/e1/f4/g1/h0/i2, 5/j2, 5/k5, 8/m0.45-0.80/ \\ n0.90-1.80/p1.20-2.40/q5 +8/r1/s3/t1/z0 New subtype Blunt triangle long margins \\ (Plate 3, Figs. 3a-f)}

Undescribed Cenozoic and Cretaceous specimens, Doyle and Riedel, 1979b, pl. 4, fig. 11 and pl. 9, fig. 16.

Characters. Elongate triangular form with lateral shadows, a blunt apex, and straight to convex outline margins that extend well below inbase. Inline arcuate or approximately same shape as outline. Inbase shape differs on opposite sides of the tooth. On one side it is straight, whereas on the other side it is curved (concave down). Because the tooth is transparent, we see two differently shaped inbases-approximately straight and concave down $(q 5+8)$. Overall length $100-260 \mu \mathrm{m}$, maximum width $80-110 \mu \mathrm{m}$.

Distinction from similar forms. Blunt apex combined with elongate margin ends distinguish this form. Narrower crescent has convex margins with curvature distributed more evenly, a less elongate form, and striations radiating from inline. Triangle complex transverse line differs in that it has a transverse line and lacks lateral shadows. Narrow triangle straight inbase is broader, with the inline extending further toward the apex of outline $(m 0.20-0.40)$.

Occurrence. Earliest occurrence in Cretaceous or older strata from DSDP 595A, 596, 596B (Table 5).

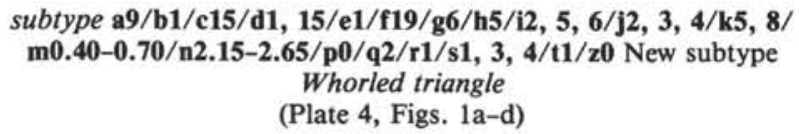

Characters. Moderately narrow triangular form (length to width ratio $2.15-2.65$ ) ornamented by a set of subparallel, curved lines extending diagonally from one margin to the other. Margins are straight, concave, or convex with upper half of margins rhythmically incised by a ridged (saw-toothed) pattern. A second set of subparallel to parallel lines runs longitudinally. Inline arcuate or about the same shape as outline. Apex of outline truncate, blunt, or between sharp and blunt. Overall length $120-190 \mu \mathrm{m}$, maximum width $50-90 \mu \mathrm{m}$.

Distinction from similar forms. Other triangular forms may have the distinctive set of curved parallel lines but lack the secondary set of longitudinal lines. Forms of Wide triangle projection (Doyle et al., 1978, pl. 3, fig. 22) are ornamented by a set of curved diagonal lines, but differ in having a triangular projection, and in the ornamented apical portion being broader (length/width ratio $<1.0$ ).

Remarks. Diagonal parallel lines may appear to form a "spiral," but the lines do not connect.

Occurrence. Earliest occurrence in Cretaceous or older strata from Holes 595a and 596 (Table 5). Late Cretaceous forms from the central North Pacific (Doyle and Riedel, 1979b, pl. 9, figs. 36, 37) and from the central equatorial Pacific (Helms and Riedel, 1971, pl. 2, figs. 2, $3,4)$ are similar to Whorled triangle but lack the set of longitudinal lines.

\section{subtype $\mathrm{a} 9 / \mathrm{b} 1 / \mathrm{c1} / \mathrm{d} 1 / \mathrm{e} 1 / \mathrm{f} 4+8+14 / \mathrm{g} 1 / \mathrm{h} 0 / \mathrm{i} 3 / \mathrm{j} 3 / \mathrm{k5} / \mathrm{m0} .30-0.50 /$ n0.90-1.50/p0/q9, 10/r1/s1, 2/t1/ z0 New subtype Pointed triangle convex margins \\ (Plate 3, Figs. 4a-d)}

Characters. Triangular form with convex margins and pronounced lateral shadows. Longitudinal striations are approximately parallel and radiate from the inline. Inline arcuate with base irregularly jagged, as if broken. Apex of outline sharp in most specimens, but may be rounded. Overall length 100-210 $\mu \mathrm{m}$, maximum width $30-160 \mu \mathrm{m}$.

Distinction from similar forms. The sharp or rounded apex and ragged base differentiate this subtype from Wide triangle keeled edges (Ramsey et al., 1976), which has a blunt apex and a smooth, concavedown inbase. The ragged inbase and convex margins distinguish this subtype from Pointed triangle arcuate inline (described below) which has a concave-down inbase and straight first margins.

Remarks. Subtle crenulations near outline margins are not sufficiently developed to be classified as a modification of the margin.

Occurrence. Earliest occurrence in Cretaceous or older strata from Holes 595 and 596 (Table 5).

subtype a9/b1/c1, 9/d1, 9/e1/f4/g1/h5/i2/j2/k0, 5/m0.70-1.00/ n1.10-1.50/p0/q6, 7/r0, 1/s1, 2/t1/z0 New subtype Simple triangle (Plate 4, Figs. 3a-f)

Characters. Triangular forms (length-to-width ratio 1.10-1.50) with lateral shadows and straight margins. A shallow angle may be present in the bottom one-fifth of each margin. Inline, if present, arcuate and restricted to the lower third of the triangle. Base is curved, concave downward. Apex of outline generally rounded (between sharp and blunt), but may be sharp. Overall length 100-360 $\mu \mathrm{m}$, maximum width $70-210 \mu \mathrm{m}$.

Distinction from similar forms. Undescribed forms similar to Simple triangle (Pl. 4, Fig. 4a, b) are more elongate (length to width ratio $>1.50$ ). Other undescribed forms (Pl. 4, Fig. 2a-c) differ in that at least one margin is concave, whereas both margins are straight in Simple triangle. Pointed triangle short inline, described above, differs in having striations radiating from the inline.

Occurrence. Earliest occurrence in Cretaceous or older strata of Holes 595A and 596 (Table 5).

$$
\begin{gathered}
\text { subtype a9/b1/c1/d1/e1/f1/g1/h5/i2, 6/j2, 3/k0, 8/m0.05-0.25/ } \\
\mathrm{n} 1.20-4.40 / \mathrm{p} 0 / \mathrm{q} 2,6 / \mathrm{r} 1 / \mathrm{s} 1,2 / \mathrm{t} 1 / \mathrm{z0} \text { New subtype } \\
\text { Narrow triangle long inline } \\
\text { (Plate 5, Figs. 1a-h) }
\end{gathered}
$$

Characters. Elongate triangular form (length to width ratio 1.204.40) with inline approximately same shape as outline, not approaching outline at base, and extending into upper quarter of outline. Margins vary in shape depending on orientation of specimen. In one view, one margin is straight or concave, the other margin convex. In the other view $\left(\right.$ at $90^{\circ}$ ), both margins are straight, or one may be slightly convex. Apex of outline sharp or rounded (between sharp and blunt). Overall length 140-270 $\mu \mathrm{m}$, maximum width $40-90 \mu \mathrm{m}$.

Distinction from similar forms. Triangle long inline (Doyle et al., 1978, pl. 2, figs. 1-3), although similar, has an inline with a drawnout, threadlike apical termination. In undescribed but similar forms (Doyle and Riedel, 1979b, pl. 9, figs. 33-35) a transverse line is present.

Occurrence. Earliest occurrence in Cretaceous or older strata from Holes 595A and 596 (Table 5).

$$
\begin{aligned}
& \text { subtype a9/b1, 5/c1/d1/e1/f4 +8 + 14/g1/h0/i2/j2, 3/k5/m0.70- } \\
& 1.60 / \mathrm{n} 0.90-1.85 / \mathrm{p} 0.70-1.60 / \mathrm{q} 6,7,8 / \mathrm{r} 1 / \mathrm{s} 1,2 / \mathrm{t1} / \mathrm{z0}, 5 / \mathrm{cc} 0,1 / \\
& \text { dd0, 1/ee0, 1/ff0, 1/gg0, 1/hh0/jj2/kk2/mm0/nn0 } \\
& \text { New subtype } \\
& \text { Pointed triangle arcuate inline } \\
& \text { (Plate 5, Figs. 4a-d) }
\end{aligned}
$$

Characters. Triangular form with lateral shadows. Both margins straight, or first margin straight and second margin slightly convex. Longitudinal striations originate from inline and are generally parallel. Apex usually sharp, occasionally rounded. Base of inline (or transverse line if present) curved (concave down). Ratio of length to width of that portion above base of inline (or transverse line), 0.90-1.85. Overall length $100-250 \mu \mathrm{m}$, maximum width $50-110 \mu \mathrm{m}$.

Distinction from similar forms. Wide triangle keeled edges (Doyle and Riedel, 1979a, pl. 7, fig. 16) differs in that it has a blunt apex and is broader (length to width ratio $0.60-0.90$ ). Pointed triangle convex margins (described in preceding text) differs in having convex margins and an irregularly jagged base, frequently with a broken-appearing lobe that extends below the lower limit of the lateral margin.

Occurrence. In Cretaceous or older strata from Holes 595A, 596, and 596B (Table 5). 
subtype a9/b1, 5/c1/d1/e1/f4 + 8 + 14/g1/h5/i4/j4/k5/m0.45-0.85/ n0.60-1.30/p1.30-2.30/q0, 3, 9/r0, 1/s3/t1/z0, 2, 5/cc0, 1/dd0, 1/ ee0, 1/ff0, 1/gg0, 3/hh0.55-0.95/jj2/kk2/mm2/nn0.35-0.80 New subtype

Triangle with humps

(Plate 5, Figs. 3a-d)

Undescribed form, southwest Indian Ocean, Doyle et al., 1974, pl. 5, fig. 13.

Undescribed form "probably late Jurassic" from Italy, Ramsey et al., 1976 , pl. 4, fig. 15 .

Characters. Triangular form, frequently with a straight transverse line and base preserved. Margins above the transverse line have a pronounced convex curvature in the lower half. Lateral shadow present on all forms. Longitudinal striations originate from inline and generally parallel each other. Inline arcuate. Base of inline (or transverse line if present) straight, terminating at sides of inline at same level. Apex of outline blunt. Overall length 100-190 $\mu \mathrm{m}$, maximum width 70-200 $\mu \mathrm{m}$.

Distinction from similar forms. The convex margins with most of the curvature basally readily distinguish this subtype.

Occurrence. Earliest occurrence in Cretaceous or older strata at Holes 595A and 596 (Table 5).

\section{subtype a9/b5/c3/d1, 3, 4/e1/f1/g1/h5/i2/j2/k0/m0/n0/p0/q0/}

$\mathrm{r0} / \mathrm{s1}, 2 / \mathrm{t1} / \mathrm{z2} / \mathrm{cc1} / \mathrm{dd} 1 / \mathrm{ee1} / \mathrm{ff1} / \mathrm{gg} 1 / \mathrm{hh0} / \mathrm{jj} 2 / \mathrm{kk} 2,3 / \mathrm{mm} 0 / \mathrm{nn} 0$ New subtype

Triangle many projections

(Plate 5, Figs. 2a-f)

Undescribed Cretaceous specimen, southeast Atlantic, Doyle et al., 1978 , pl. 3, fig. 27

Characters. Elongate triangular form with distinctive triangular projections (more than one) around the apical half. Outline margins are straight and apex is sharp or rounded (between sharp and blunt). Overall length 90-300 $\mu \mathrm{m}$, maximum width 60-130 $\mu \mathrm{m}$.

Distinction from similar forms. This subtype is easily distinguished by the total number of triangular projections (always more than one). Wide triangle projection is similar but has only one triangular projection.

Occurrence. Earliest occurrence in Cretaceous or older strata from Holes 595A and 596.

\section{ACKNOWLEDGMENTS}

This research was supported partly by NSF Grant OCE82-14587, the Deep Sea Drilling Project, and the University of California. L. E. Tway made valuable suggestions during the course of this study. We thank M. B. Hart and A. Kaneps for their thoughtful reviews of the manuscript. S. M. Green and Carol Pittman provided assistance in various phases of the manuscript.

\section{REFERENCES}

Dengler, A. T., Doyle, P. S., and Riedel, W. R., 1975. Ichthyoliths in some samples from the Philippine Sea, DSDP Leg 31. In Karig, D. E., Ingle, J. C., et al.,Init. Repts. DSDP, 31: Washington (U.S. Govt. Printing Office), 821-833.

Doyle, P. S., Dunsworth, M. J., and Riedel, W. R., 1978. Ichthyoliths from some southeast Atlantic sediments, DSDP Leg 40. In Bolli, H. M., Ryan, W. B. F., et al., Init. Repts. DSDP, Suppl. to Vols. $38,39,40,41$ : Washington (U.S. Govt. Printing Office), 743-759.

Doyle, P. S., Kennedy G. G., and Riedel, W. R., 1974. Stratignathy. In Davies, T. A., Luyendyk, B. P., et al., Init. Repts. DSDP, 26: Washington (U.S. Govt. Printing Office), 825-905.

Doyle, P. S., and Riedel, W. R., 1979a. Ichthyoliths: Present Status of Taxonomy and Stratigraphy of Microscopic Fish Skeletal Debris. Scripps Institution of Oceanography Reference Series, Number 7916: Springfield, Va. (National Technical Information Service Publications).

1979b. Cretaceous to Neogene ichthyoliths in a giant piston core from the central North Pacific. Micropaleontology, 25:337364.

1980. Ichthyoliths from Site 436, Northwest Pacific, Leg 56, Deep Sea Drilling Project. In Scientific Party, Init. Repts. DSDP, 56, 57, Pt. 2: Washington (U.S. Govt. Printing Office), 887-893.
1981. Ichthyoliths at Site 464 in the Northwest Pacific, Deep Sea Drilling Project, Leg 62. In Thiede, J., Vallier, T. L., et al., Init. Repts. DSDP, 62: Washington (U.S. Govt. Printing Office), 491494.

1985a. Cenozoic and Late Cretaceous ichthyoliths. In Bolli, H. M., Perch-Nielsen, K., and Saunders, J. B. (Eds.), Plankton Stratigraphy: Cambridge (Cambridge University Press).

1985b. Ichthyolith biostratigraphy from western North $\mathrm{Pa}$ cific pelagic clays, DSDP Leg 86 . In Burckle, L. H., Heath, G. R. et al., Init. Repts. DSDP, 86: Washington (U.S. Govt. Printing Office), 349-366.

Dunsworth, M. J., Doyle, P. S., and Riedel, W. R., 1975. Ichthyoliths from some northwest Pacific sediments, DSDP Leg 32. In Larson R. L., Moberly, R., et al., Init. Repts. DSDP, 32: Washington (U.S. Govt. Printing Office), 853-863.

Edgerton, C. C., Doyle, P. S., and Riedel, W. R., 1977. Ichthyolith age determinations of otherwise unfossiliferous Deep Sea Drilling Project cores. Micropaleontology, 23:194-205.

Gottfried, M. D., Doyle, P. S., and Riedel, W. R., 1984. Advances in ichthyolith stratigraphy of the Pacific Neogene and Oligocene. $M i$ cropaleontology, 30:71-85.

1985. Stratigraphic interpretations of pelagic sequences revised on the basis of ichthyoliths. Micropaleontology, 30:71-85.

Helms, P. B., and Riedel, W. R., 1971. Skeletal debris of fishes. In Winterer, E. L., Riedel, W. R., et al., Init. Repts. DSDP, 7, Pt. 2: Washington (U.S. Govt. Printing Office), 1709-1720.

Kaneps, A. G., Doyle, P. S., and Riedel, W. R., 1981. Further ichthyoliths age determinations of otherwise unfossiliferous Deep Sea Drilling Project cores. Micropaleontology, 27:317-331.

Okada, H., and Bukry, D., 1980. Supplementary modification and introduction of code numbers to the low-latitude coccolith biostratigraphic zonation (Bukry, 1973; 1975). Mar. Micropaleontol. 5: 321-325.

Ramsey, C. A., Doyle, P. S., and Riedel, W. R., 1976. Ichthyoliths in Late Mesozoic pelagic sediments, mainly from Italy. Micropaleontology, 22:129-142.

Riedel, W. R., and Westberg, M. J., 1982. Neogene radiolarians from the eastern tropical Pacific and Caribbean, DSDP Leg 68. In Prell, W. L., Gardner, J. V., et al., Init. Repts. DSDP, 68: Washington (U.S. Govt. Printing Office), 289-300.

Shackleton, N. J., and Members of the Shipboard Scientific Party, 1984. Accumulation rates in Leg 74 sediments. In Moore, T. C., Jr., Rabinowitz, P. D., et al., Init. Repts. DSDP, 74: Washington (U.S. Govt. Printing Office), 621-644.

Tway, L. E., Doyle, P. S., and Riedel, W. R., 1985. Correlation of dated and undated Pacific samples based on ichthyoliths and clustering techniques. Micropaleontology, 31:295-319.

Westberg, M. J., and Riedel, W. R., 1982. Radiolarians from the MidAmerica trench off Guatemala, Deep Sea Drilling Project Leg 67. In Von Huene, R., Aubouin, J., et al., Init. Repts. DSDP, 67: Washington (U.S. Govt. Printing Office), 401-424.

\section{Date of Initial Receipt: 17 August 1984}

Date of Acceptance: 9 December 1984

\section{APPENDIX}

Subtypes present at Sites 595 and 596 are listed under "List of Taxa Present," and those not present but looked for are listed under "List of Taxa Not Present" by colloquial name in alphabetical order. Each is followed by reference(s) to the current concept of the subtype.

\section{List of Taxa Present}

Asymmetrical peak depression, Gottfried et al., 1984.

Asymmetrical peaks narrow depression, Doyle et al., 1974; emend. Doyle and Riedel, 1979a.

Attenuated with pores, Tway et al., 1985.

Beveled triangle concave margins, Doyle and Riedel, 1985b.

Beveled triangle high inline, Doyle et al., 1978; emend. Doyle and Riedel, 1979a.

Beveled triangle mid inline, Doyle et al., 1978; emend. Doyle and Riedel, 1979a.

Blunt triangle dendritic inline, Doyle et al., 1978; emend. Doyle and Riedel, 1979a.

Blunt triangle long margins, Winfrey et al., new subtype. 
Broad triangle parallel inline, Gottfried et al., 1984.

Capped triangle, Ramsey et al., 1976; emend. Doyle and Riedel, 1979a.

Centrally striated triangle, Doyle et al., 1978; emend. Doyle and Riedel, 1979a; emend. herein.

Circular with line across, Doyle et al., 1974; emend. Edgerton et al., 1977; emend. Doyle and Riedel, 1979a.

Circular with pores, Tway et al., 1985.

Crossed kite, Winfrey et al., new subtype.

Curved fibrous triangle, Tway et al., 1985.

Curved flared triangle, Ramsey et al., 1976; emend. Doyle and Riedel, 1979a.

Curved triangle inline constricted, Doyle et al., 1974; emend. Doyle and Riedel, 1979a.

Curved triangle pointed inline, Gottfried et al., 1984.

Curved triangle pointed margin, Doyle et al., 1974; emend. Doyle and Riedel, 1979a.

Elliptical with line across, Doyle et al., 1974; emend. Edgerton et al., 1977; emend. Doyle and Riedel, 1979a.

Fibrous triangle convex margins, Tway et al., 1985.

Five peaks flared base, Doyle et al., 1974; emend. Doyle and Riedel, 1979a.

Flared triangle arcuate inline, Ramsey et al., 1976; emend. Doyle and Riedel, 1979a.

Flexed triangle asymmetric, Doyle and Riedel, $1985 \mathrm{~b}$.

Flexed triangle shallow inbase, Doyle et al., 1974.

Flexed triangle shallow inbase $>=120$, Dunsworth et al., 1975; emend. Edgerton et al., 1977; emend. Doyle and Riedel, 1979a.

Giant lanceolate, Doyle et al., 1974; emend. Doyle and Riedel, 1979a.

Kite-shaped elongate prominence, Doyle et al., 1974; emend. Doyle and Riedel, 1979a.

Lanceolate median line, Winfrey et al., new subtype.

Large fibrous triangle, Tway et al., 1985.

Large with numerous lines, Doyle et al., 1974; emend. Doyle and Riedel, 1979a.

Lined lanceolate differentiated margin, Tway et al., 1985.

Long ellipse, Gottfried et al., 1984.

Long rectangular with striations, Doyle et al., 1974; emend. Doyle and Riedel, 1979a.

Long triangle short inline, Gottfried et al., 1984.

Long triangle stepped margin, Doyle et al., 1974; emend. Edgerton et al., 1977; emend. Doyle and Riedel, 1979a.

Long triangle thin wall, Dunsworth et al., 1975; emend. Doyle and Riedel, 1979a.

Many peaks transverse lines, Tway et al., 1985.

Narrow curved triangle small top, Ramsey et al., 1976; emend. Doyle and Riedel, 1979a.

Narrow curved triangle, Doyle et al., 1974; emend. Doyle and Riedel, 1979a.

Narrow lanceolate undulating margin, Tway et al., 1985.

Narrow triangle cross-hachured, Doyle et al., 1974; emend. Doyle and Riedel, 1979a.

Narrow triangle long inline, Winfrey et al., new subtype.

Narrow triangle ragged base, Dunsworth et al., 1975; emend. Doyle and Riedel, 1979a.

Narrow triangle sharply pointed, Ramsey et al., 1976; emend. Doyle and Riedel, 1979a.

Narrow triangle straight inbase, Doyle et al., 1974; emend. Doyle and Riedel, 1979a.

Narrow triangle unequal margins, Doyle and Riedel, 1985b.

Ogee lanceolate, Tway et al., 1985.

Plain and lined lanceolate, Doyle et al., 1974; emend. Doyle and Riedel, 1979a; emend. herein.

Pointed and skirted, Doyle et al., 1978; emend. Doyle and Riedel, 1979a.

Pointed triangle arcuate inline, Winfrey et al., new subtype.

Pointed triangle convex margins, Winfrey et al., new subtype.

Pointed triangle long margins, Gottfried et al., 1984.

Polygon with cross, Winfrey et al., new subtype.

Polygon with skewed cross, Winfrey et al., new subtype.

Prominence with wye-line, Doyle et al., 1978; emend. Doyle and Riedel, 1979a.

Prominent polygon, Doyle et al., 1978.

Rectangular irregularly saw-toothed, Doyle et al., 1974; emend. Doyle and Riedel, 1979a.
Rectangular peaked projections, Tway et al., 1985.

Rhombus smooth margin, Doyle et al., 1974; emend. Doyle and Riedel, 1979a.

Rhombus undulating margin, Doyle et al., 1974; emend. Doyle and Riedel, 1979a.

Rounded apex triangle, Doyle et al., 1974.

Saw-toothed arcuate inline, Tway et al., 1985.

Saw-toothed transverse lines, Tway et al., 1985.

Saw-toothed with striations, Tway et al., 1985.

Scalloped polygon, Winfrey et al., new subtype.

Short rectangular with striations, Doyle et al., 1974; emend. Doyle and Riedel, 1979a.

Short side peaks undulating margin, Tway et al., 1985.

Short triangle bowed inline, Doyle et al., 1978; emend. Doyle and Riedel, 1979a.

Short triangle stepped margin, Doyle et al., 1974; emend. Edgerton et al., 1977; emend. Doyle and Riedel, 1979a.

Simple triangle, Winfrey et al., new subtype.

Skewed four or five peaks, Doyle et al., 1974; emend. Doyle and Riedel, 1979a.

Skewed with transverse lines, Doyle et al., 1974; emend. Doyle and Riedel, 1979a.

Small circular center, Doyle et al., 1974; emend. Doyle and Riedel, 1979 a.

Small dendritic few radiating lines, Doyle et al., 1974; emend. Doyle and Riedel, 1979a.

Small dendritic many radiating lines, Doyle et al., 1974.

Small pointed triangle, Tway et al., 1985.

Small skewed lanceolate, Tway et al., 1985.

Small triangle hooked margin, Tway et al., 1985.

Small triangle keeled edges, Ramsey et al., 1976; emend. Doyle and Riedel, 1979a.

Small triangle long striations, Dunsworth et al., 1975; emend. Doyle and Riedel, 1979a; emend. Kaneps et al., 1981; emend. Doyle and Riedel, in press, a.

Small triangle many canals, Tway et al., 1985.

Spiky palmate, Doyle and Riedel, 1980.

Stippled triangle, Dunsworth et al., 1975; emend. Doyle and Riedel, 1979a.

Straight flared triangle, Ramsey et al., 1976; emend. Doyle and Riedel, 1979a.

Straight triangle keeled edges, Ramsey et al., 1976; emend. Doyle and Riedel, 1979a.

Striated blunt triangle, Doyle et al., 1978; emend. Doyle and Riedel, 1979a.

Tanged triangle, Gottfried et al., 1984.

Three equal peaks flared base, Doyle et al., 1974; emend. Doyle and Riedel, 1979a.

Three narrow peaks, Tway et al., 1985.

Three peaks transverse lines, Tway et al., 1985.

Three similar peaks, Doyle et al., 1974; emend. Doyle and Riedel, 1979a.

Three tall peaks, Dunsworth et al., 1975; emend. Doyle and Riedel, 1979a.

Triangle bowed inline, Ramsey et al., 1976; emend. Doyle and Riedel, 1979a; emend. herein.

Triangle complex transverse line, Doyle et al., 1974; emend. Doyle and Riedel, 1979a.

Triangle concave base, Doyle et al., 1978; emend. Doyle and Riedel, $1979 \mathrm{a}$.

Triangle crenulate, Doyle et al., 1974; emend. Doyle and Riedel, 1979a.

Triangle curved base, Doyle et al., 1978; emend. Doyle and Riedel, 1979a.

Triangle curved pointed margins, Doyle and Riedel, 1985b.

Triangle double flex, Dunsworth et al., 1975; emend. Doyle and Riedel, 1979a.

Triangle hooked margin, Doyle et al., 1974; emend. Doyle and Riedel, 1979a.

Triangle inline halfway, Doyle et al., 1974; emend. Doyle and Riedel, 1979a.

Triangle keeled edges, Ramsey et al., 1976; emend. Doyle and Riedel, 1979a.

Triangle long inline, Doyle et al., 1978; emend. Doyle and Riedel, 1979 a. 
Triangle many projections, Winfrey et al., new subtype.

Triangle medium wing, Doyle et al., 1974; emend. Doyle and Riedel, 1979a.

Triangle one canal above, Doyle et al., 1974; emend. Doyle and Riedel, 1979a.

Triangle pointed margin ends, Doyle et al., 1974; emend. Doyle and Riedel, 1979a.

Triangle radiating inline, Doyle and Riedel, 1985b.

Triangle short base, Tway et al., 1985.

Triangle short wing, Doyle et al., 1974; emend. Doyle and Riedel, 1979a.

Triangle sigmoid rough, Ramsey et al., 1976; emend. Doyle and Riedel, 1979a.

Triangle sigmoid, Dunsworth et al., 1975; emend. Edgerton et al., 1977; emend. Doyle and Riedel, 1979a.

Triangle sinuous inline, Gottfried et al., 1984.

Triangle small top, Ramsey et al., 1976; emend. Doyle and Riedel, 1979a.

Triangle smooth surface, Doyle and Riedel, 1980.

Triangle square inline, Doyle et al., 1978; emend. Edgerton et al., 1977; emend. Doyle and Riedel, 1979a.

Triangle trailing margin, Ramsey et al., 1976; emend. Doyle and Riedel, 1979a.

Triangle transverse line across, Doyle et al., 1974; emend. Doyle and Riedel, 1979a.

Triangle undulating margins, Tway et al., 1985.

Triangle with base angle, Dunsworth et al., 1975; emend. Doyle and Riedel, 1979a.

Triangle with canals, Doyle et al., 1974; emend. Doyle and Riedel, 1979a.

Triangle with high inline apex, Doyle et al., 1974; emend. Doyle and Riedel, 1979a.

Triangle with humps, Winfrey et al., new subtype.

Triangle with parallel inline, Doyle et al., 1974; emend. Doyle and Riedel, 1979a.

Triangle with triangular projection, Doyle et al., 1974; emend. Doyle and Riedel, 1979a.

Triangular toothed, Doyle et al., 1974; emend. Doyle and Riedel, 1979a.

Two triangles, Doyle et al., 1974; emend. Doyle and Riedel, 1979a.

Whorled triangle, Winfrey et al., new subtype.

Wide crescent, Doyle et al., 1978; emend. Doyle and Riedel, 1979a.

Wide triangle keeled edges, Ramsey et al., 1976; emend. Doyle and Riedel, 1979a.

Wide triangle projection, Doyle et al., 1978; emend. Doyle and Riedel, 1979a.
Wide triangle straight inbase, Doyle et al., 1974; emend. Doyle and Riedel, 1979a.

Wide triangle, Dunsworth et al., 1975; emend. Doyle and Riedel, 1979a.

\section{List of Taxa Not Present}

Asymmetrical peak wide depression, Doyle et al., 1974.

Asymmetrical two peaks depression, Doyle et al., 1974.

Kite-shaped irregular network, Doyle et al., 1974; emend. Doyle and Riedel, 1979a.

Kite-shaped longitudinal line, Doyle et al., 1974; emend. Doyle and Riedel, 1979a.

Large triangle saw-toothed margin, Dunsworth et al., 1977.

Long saw-toothed, Tway et al., 1985.

Narrow straight triangle, Gottfried et al., 1984.

Narrow crescent, Doyle et al., 1974; emend. Doyle and Riedel, 1979a.

Pointed triangle short inline, Gottfried et al., 1984.

Rectangular saw-toothed, Dunsworth et al., 1975; emend. Doyle and Riedel, 1979a.

Short kite-shaped, Doyle et al., 1974; emend. Doyle and Riedel, 1979a.

Short side peaks differentiated margin, Doyle et al., 1974; emend. Doyle and Riedel, 1979a.

Small triangle crenate margin, Dunsworth et al., 1975; emend. Doyle and Riedel, 1979a.

Striated triangle, Ramsey et al., 1976; emend. Doyle and Riedel, 1979a.

Tall median peak transverse lines, Doyle et al., 1974; emend. Doyle and Riedel, 1979a.

Tall triangle low inline, Ramsey et al., 1976; emend. Doyle and Riedel, 1979a.

Triangle arcuate inline, Ramsey et al., 1976; emend. Doyle and Riedel, 1979a.

Triangle broad wing, Doyle et al., 1974; emend. Edgerton et al., 1977; emend. Doyle and Riedel, 1979a.

Triangle concave first margin, Gottfried et al., 1984.

Triangle double inline, Gottfried et al., 1984.

Triangle inward angle, Gottfried et al., 1984.

Triangle irregular base, Gottfried et al., 1984.

Triangle notched corner, Doyle et al., 1974; emend. Doyle and Riedel, 1979a.

Two curved triangle, Doyle et al., 1974; emend. Doyle and Riedel, 1979a.

Two curved triangles long base, Doyle et al., 1974; emend. Doyle and Riedel, 1979a. 


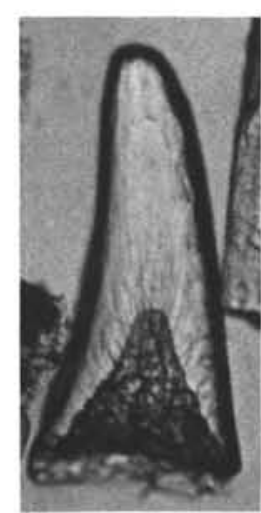

$1 \mathrm{a}$

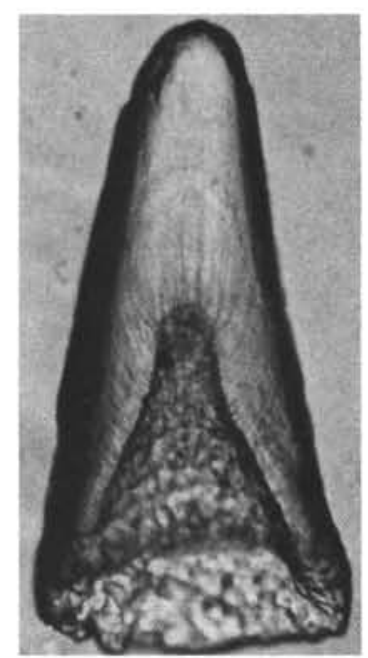

$1 \mathrm{~b}$
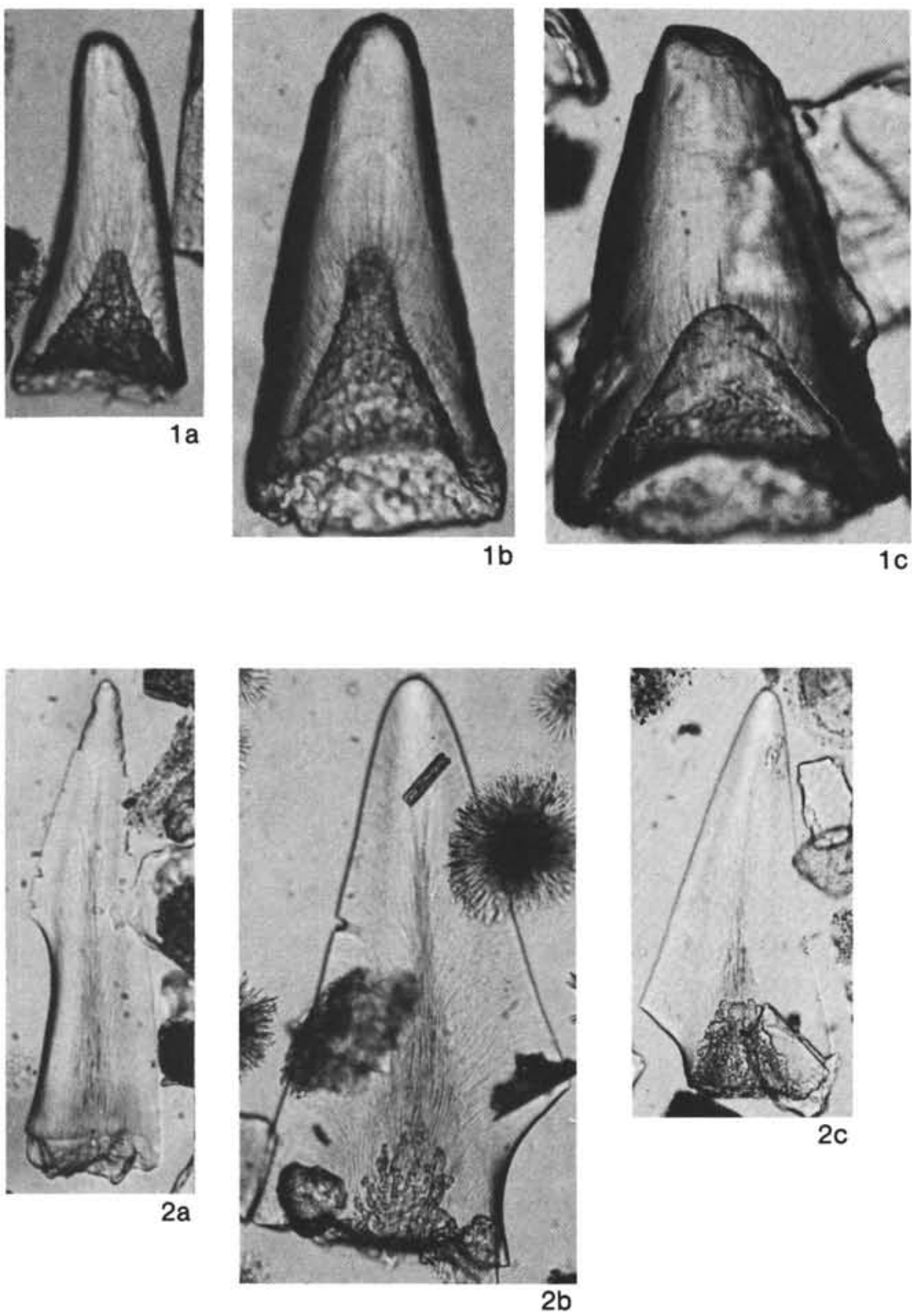
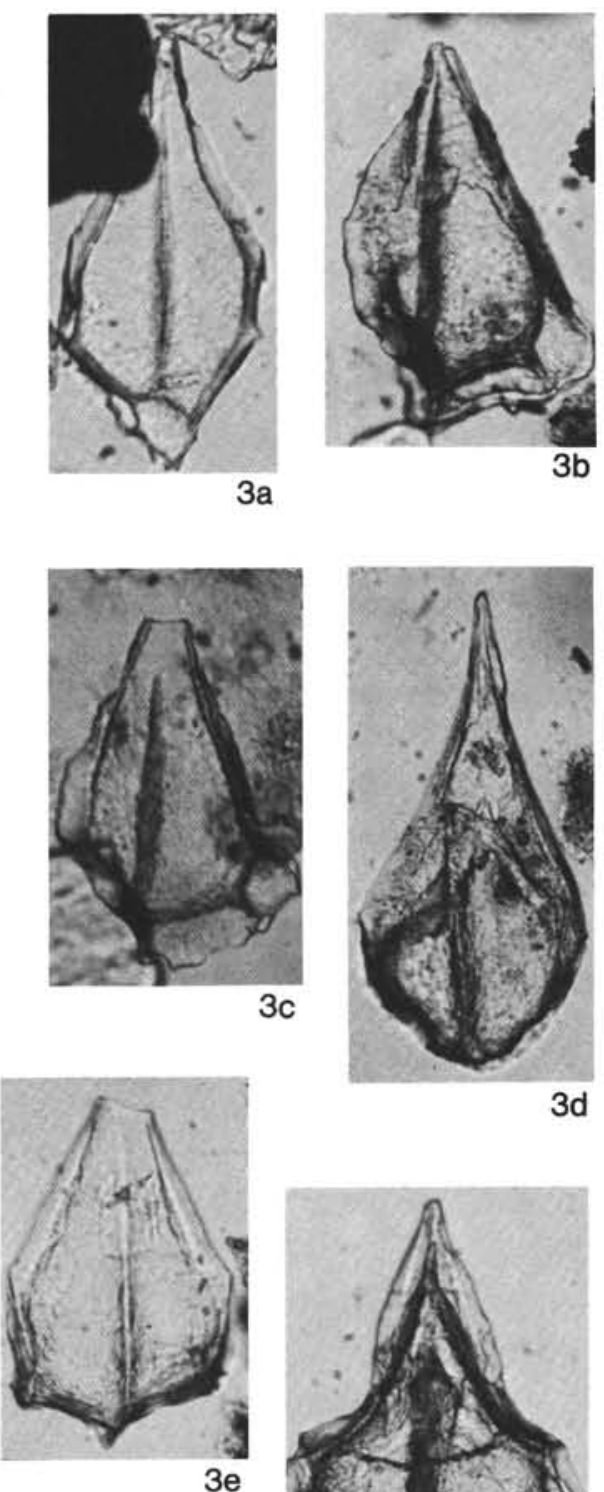

$3 d$

Plate 1. (Magnification $\times 163$ unless otherwise indicated). 1a-c. subtype a9/b1/c1/d1/e1/f4+8+15/g1/h5/i2,6/j2,3/k3/m0.40-0.60/n1.402.30/p0/q2,6/r1/s1,3/t1/z0 Ramsey et al., 1976; Doyle and Riedel, 1979; emend. herein. Triangle bowed inline. (a) 595A-4-2, 64-66 cm, S1.631, X12; (b) 595A-4-2, 60-64 cm, S1.63-1, F8; (c) 596-6-3, 81-84 cm, S1.63-1, J2. 2a-c. subtype a9/b1/c1/d1/e1/f10 + (12,13) + 14/g1/h3,4,5/ i2/j2/k0,11/m0/n1.10-1.60/p.1.10-1.70/q2,3,4,9/r1/s1/t1 + a8/b1,5/c1/d1,2/e88-93/f29-40/g1,2/h0 Doyle et al., 1978; Doyle and Riedel, 1979; emend. herein. Centrally striated triangle. (a) 595A-3,CC (108-111 cm), S1.2, S30; (b) 595A-4-6, 22-27 cm, Sl.63-6, M20; (c) 595A-3-3, 50-

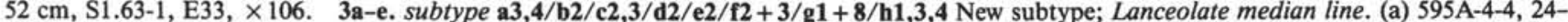
$29 \mathrm{~cm}$, S1.63-3, G48; (b) 596-6-4, 60-66 cm, S1.63-5, J31; (c) 595A-4-4, 24-29 cm, S1.63-1, P33; (d) 596-5,CC, S1.63-2, X17, type specimen; (e) $595 \mathrm{~A}-5-1,82-85 \mathrm{~cm}, \mathrm{~S} 1.63-2, \mathrm{X} 14$. 4. Undescribed form similar to Lanceolate median line; differs in height of acute prominence and concavity of sides of acute prominence. $595 \mathrm{~A}-5-1,82-85 \mathrm{~cm}, \mathrm{~S} 1.63-2, \mathrm{~J} 49$. 


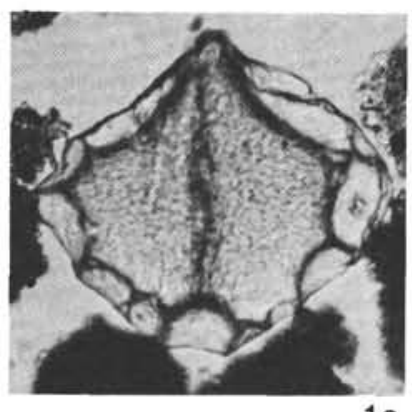

1a
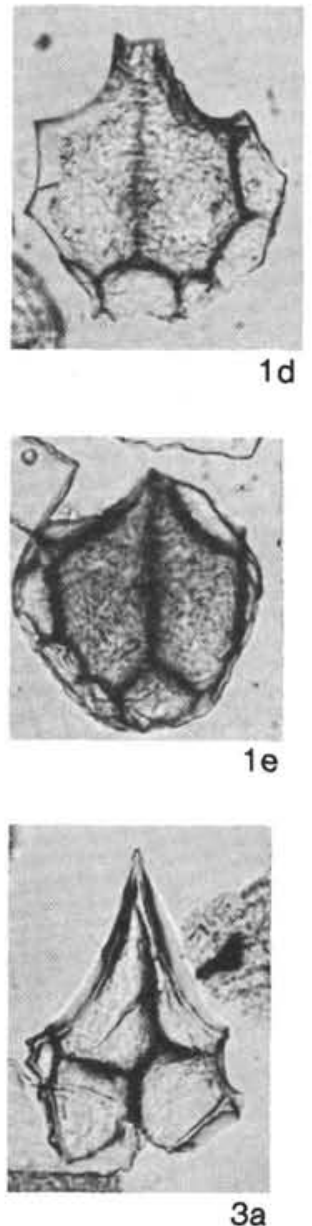
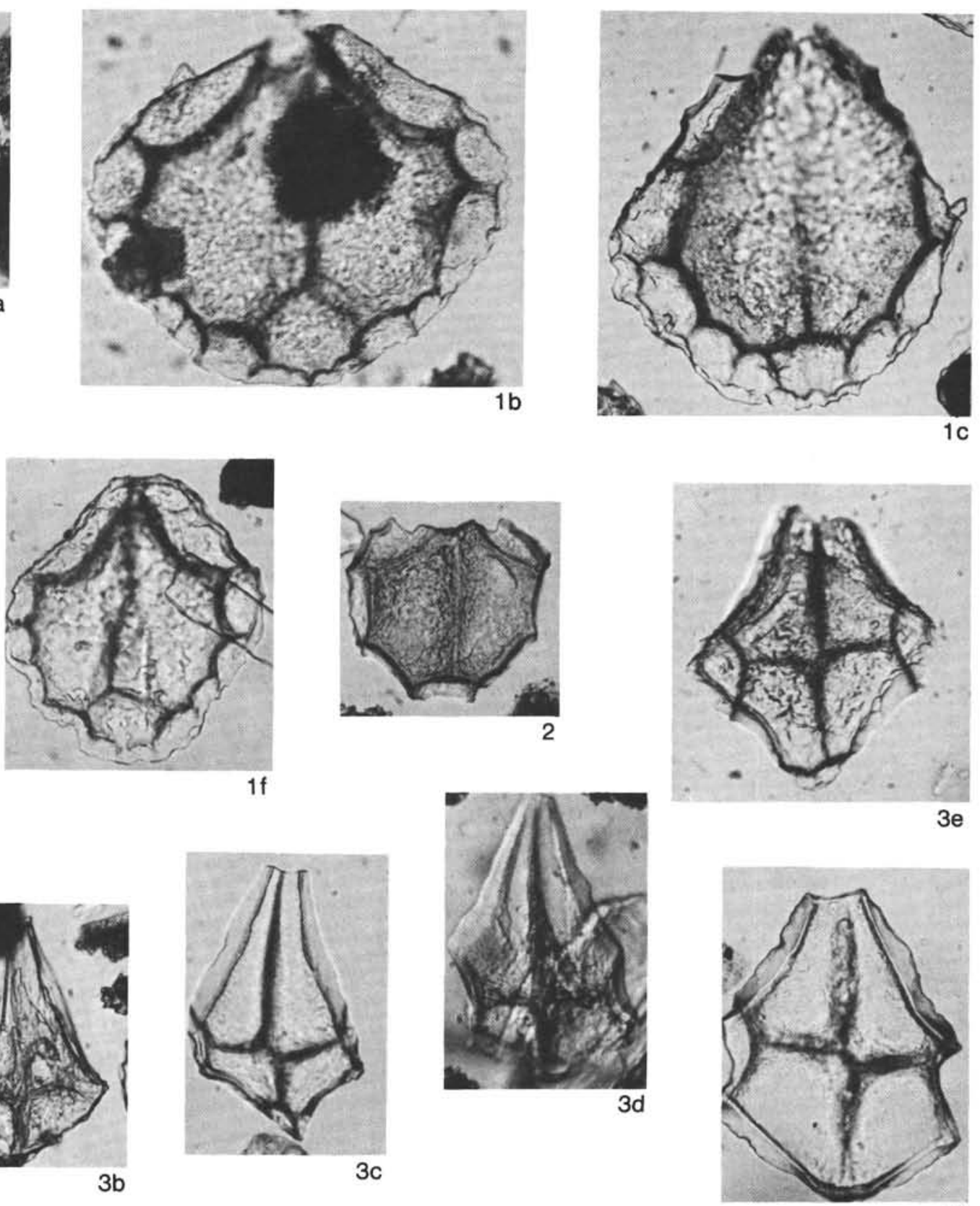

$3 f$

Plate 2. (Magnifications $\times 163$.) 1a-f. subtype a3/b8/c9-12/d0.20-0.30/e110-320/f1 + a4/b1/c2/d2,3/e0/f2 + 3/g4,8/h1,4 New subtype; Scalloped polygon. (a) 596-6-3, 63-67 cm, S1.63-4, G7, type specimen; (b) 596-5-4, 81-84 cm, S1.63-5, U22; (c) 595A-4-2, 60-64 cm, S1.63-1, O15; (d) 596-5-3, 81-84 cm, S1.63-1, Y21; (e) 595A-4-4, 24-29 cm, S1.63-2, F28; 2. Undescribed form similar to Scalloped polygon but lacks scalloped edge and has fewer than nine sides. 595A-5-7, 30-37 cm, S1.63-1, L34. 3a-f. subtype a3/b10/c1/d1,2. New subtype; Crossed kite. (a) 595A-3-3, 55-57 cm, S1.63-1, R28; (b) 596-6-4, 60-66 cm, S1.63-9, C29; (c) 595A-3-3, 50-52 cm, S1.63-2, N33, type specimen; (d) 595A-4-6, 22$27 \mathrm{~cm}, \mathrm{~S} 1.63-1$, T29; (e) 596-6-4, 60-66 cm, S1.63-8, Y1; (f) 595A-4-2, 60-64 cm, S1.63-2, R11. 


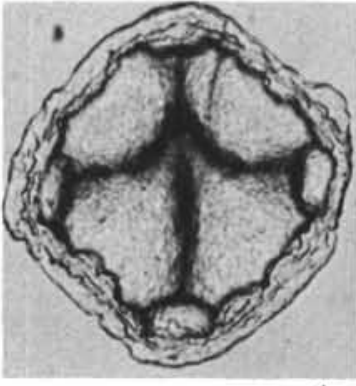

1a

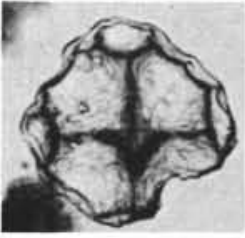

$1 d$
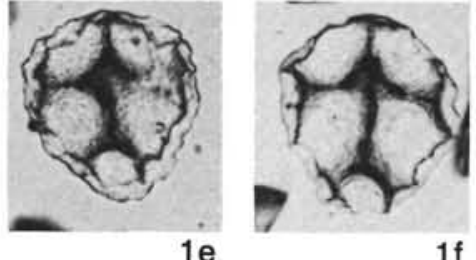

$1 f$
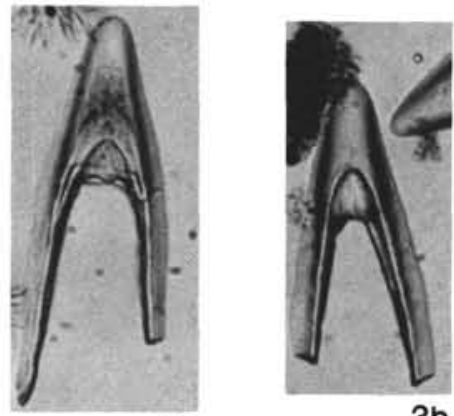

$3 a$

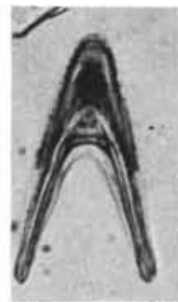

3d

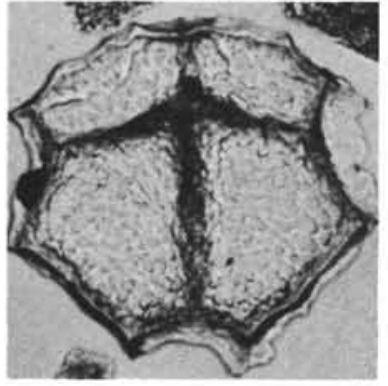

1b

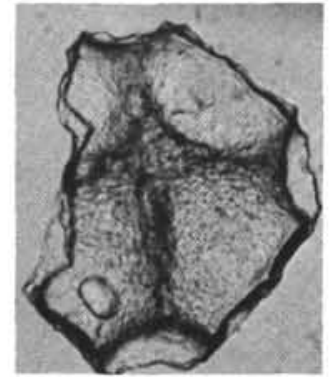

$1 c$
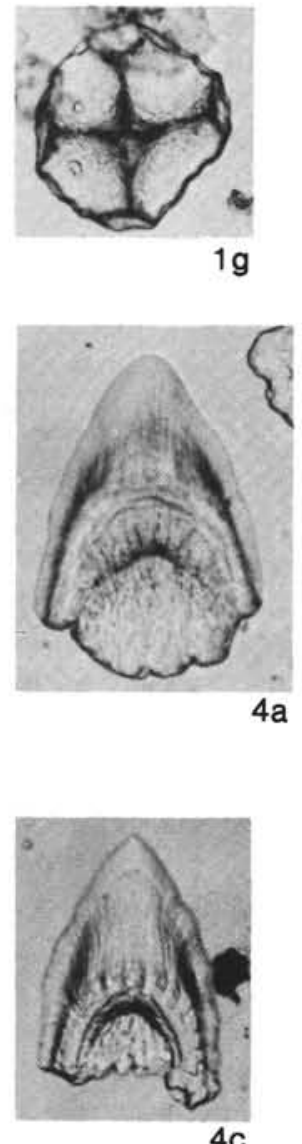
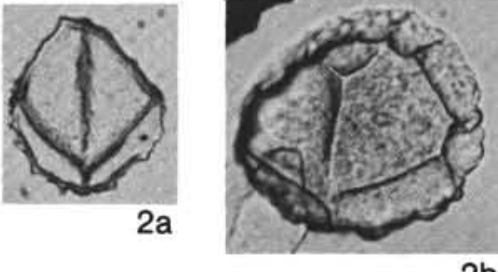

$2 b$

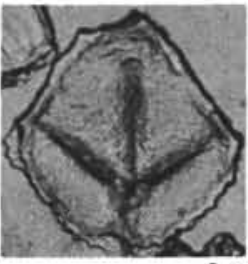

2c
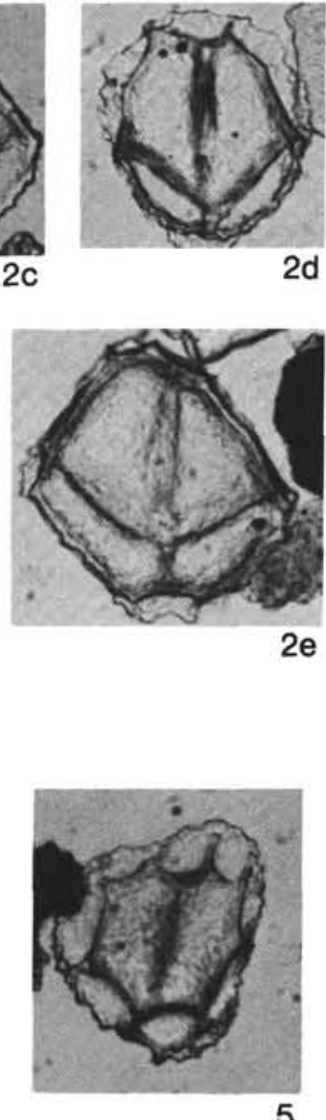

Plate 3. (Magnifications $\times 163$.) 1a-g. subtype a3,5/b10/c2/d2 New subtype; Polygon with cross. (a) 596A-1-2, 92-98 cm, S1.63-1, S46; (b) 595A-4-2, 60-64 cm, S1.63-1, X21, type specimen; (c) 595A-4-4, 24-29 cm, S1.63-3, B12; (d) 595A-8-3, 130-136 cm, S1.63-3, N35; (e) 595A-8-3, 130-136 cm, S1.63-2, O26; (f) 596A-1-1, 70-78 cm, S1.63-10, H20; (g) 596A-1-1, 70-78 cm, S1.63-7, S36; 2a-e. subtype a3,5/b10/c2/d3 New subtype; Polygon with skewed cross. (a) 595A-4-6, 22-27 cm, S1.63-5, N22; (b) 595A-4-4, 24-29 cm, S1.63-1, D36; (c) 595A-4-6, 23-27 cm, S1.63-3, F22; (d) 596-3-5, $108-111 \mathrm{~cm}, \mathrm{~S} 1.63-1, \mathrm{R} 21$, type specimen; (e) 596B-1-4, 79-82 cm, S1.63-1, F34. 3a-f. subtype a9/b1/c1/d1/e1/f4/ $\mathrm{g} 1 / \mathrm{h} 0 / \mathrm{i} 2,5 / \mathrm{j} 2,5 / \mathrm{k5}, 8 / \mathrm{m} 0.45-0.80 / \mathrm{n} 0.90-1.80 / \mathrm{p} 1.20-2.40 / \mathrm{q5}+8 / \mathrm{r1} / \mathrm{s} 3 / \mathrm{t} 1 / \mathrm{z0}$ New subtype; Blunt triangle long margins. (a) $595 \mathrm{~A}-4-6,22-27$ cm, S1.63-2, C40; (b) 596-6-1, 85-88 cm, S1.63-1, R11, type specimen; (c) 595A-4-3, 24-29 cm, S1.63-2, N18; (d) 595A-4-6, 22-27 cm, S1.63-2, V27; (e) 596B-1,CC, S1.63-1, L19; (f) 595A-4-6, 22-27 cm, S1.63-1, H30. 4a-d. subtype a9/b1/c1/d1/e1/f4+8 +14/g1/h0/i3/j3/k5/m0.300.50/n0.90-1.50/p0/q9,10/r1/s1,2/t1/z0 New subtype; Pointed triangle convex margins. (a) $595 \mathrm{~A}-4-4,24-29 \mathrm{~cm}$, S1.63-3, O13, type specimen; (b) 596-6-4, 60-66 cm, S1.63-8, J11; (c) 595A-4-4, 24-29 cm, S1.63-3, E14; (d) 595A-5-7, 30-37 cm, S1.63-2, B43. 5. Undescribed form similar to Polygon with cross and Polygon with skewed cross but does not have crossed lines. 596B-1,CC, S1.63-1, X28. 
E. C. WINFREY, P. S. DOYLE, W. R. RIEDEL
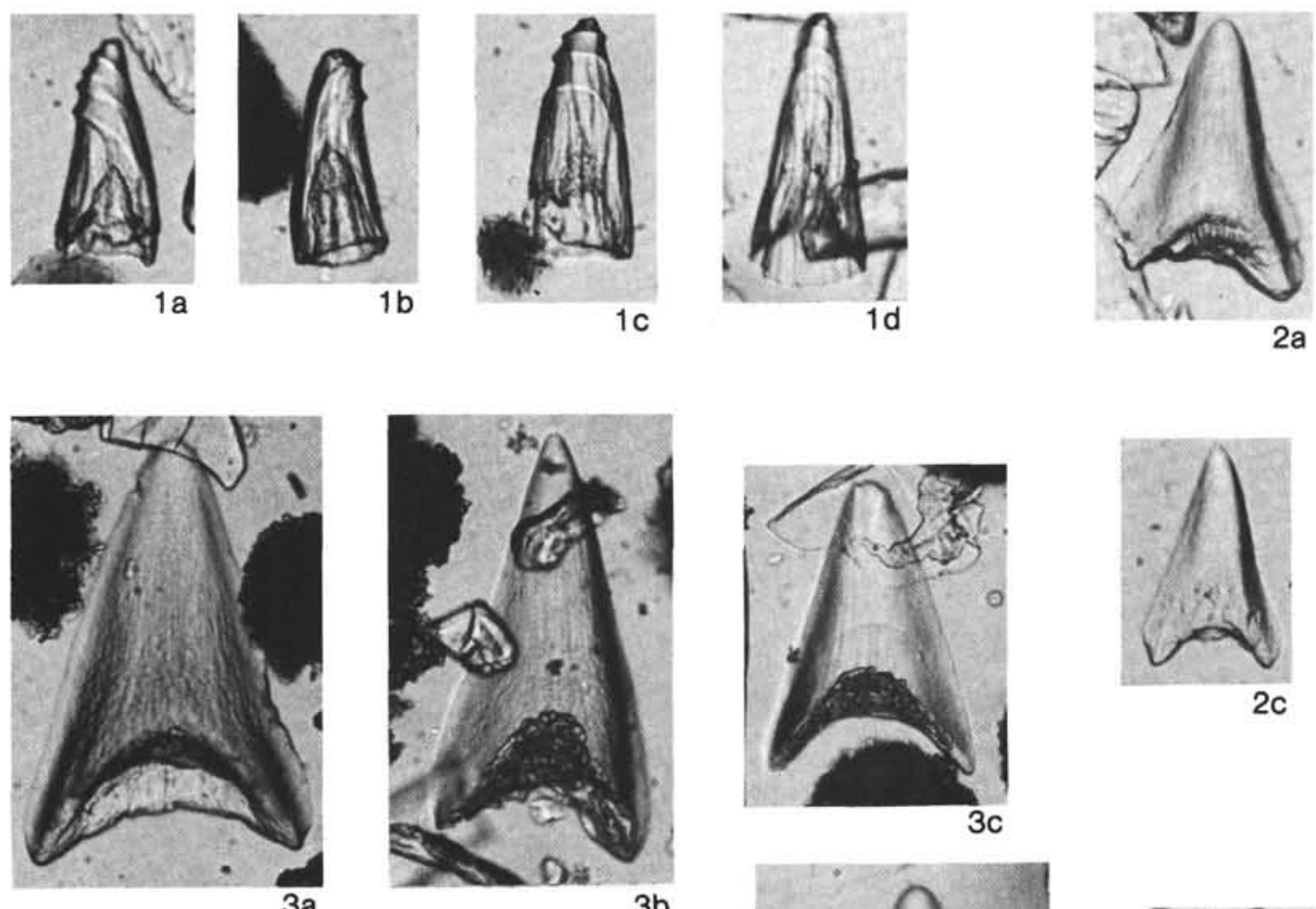

3b
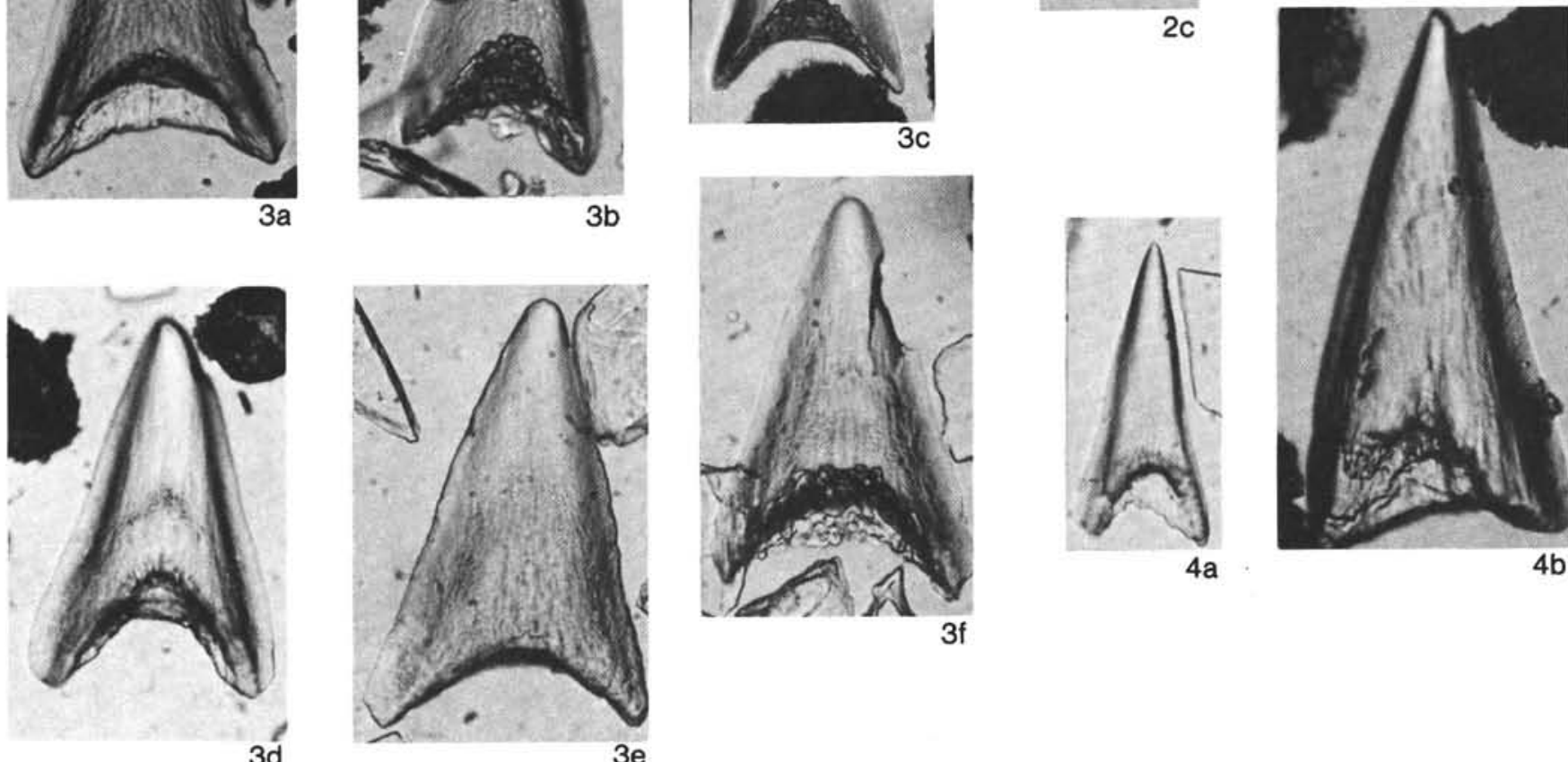

$4 b$

Plate 4. (Magnification $\times 163$.) 1a-d. subtype a9/b1/c15/d1,15/e1/f19/g6/h5/i2,5,6/j2,3,4/k5,8/m0.40-0.70/n2.15-2.65/p0/q2/r1/s1,3,4/t1/z0 New subtype; Whorled triangle. (a) 595A-3-2, 50-55 cm, S1.63-1, S41, type specimen; (b) 596-3-4, 108-111 cm, S1.63-1, H14; (c) 596-3-4, 108$111 \mathrm{~cm}, \mathrm{~S} 1.63-1, \mathrm{~K} 32$; (d) 596-3-4, 108-111 cm, S1.63-1, O16. 2a-c. Undescribed forms similar to Simple triangle. These differ in that they have at least one concave margin instead of both margins straight. (a) $595 \mathrm{~A}-5-7,30-37 \mathrm{~cm}, \mathrm{~S} 1.63-3$, U23; (b) $595 \mathrm{~A}-4-2,60-64 \mathrm{~cm}, \mathrm{~S} 1.63-1, \mathrm{X} 34$; (c) 596-6-4, 60-64 cm, S1.63-2, F16. 3a-f. subtype a9/b1/c1,9/d1,9/e1/f4/g1/h5/i2/j2/k0,5/m0.70-1.00/n1.10-1.50/p0/q6,7/r0,1/s1,2/t1/ z0 New subtype; Simple triangle. (a) 596-6-4, 60-66 cm, S1.63-2, K44; (b) 596-6-4, 60-66 cm, S1.63-1, T36; (c) 596-6-4, 60-66 cm, S1.63-5, H26, type specimen; (d) 596-6-3, 63-67 cm, S1.63-3, L10; (e) 596-5-3, 81-84 cm, S1.63-1, C18; (f) 596-5-2, 81-84 cm, S1.63-2, L30. 4a,b. Undescribed forms similar to Simple triangle but differing in that these are more elongate ( $\mathrm{n}>1.50$ ). (a) $596-5-2,81-84 \mathrm{~cm}, \mathrm{~S} 1.63-2,019$; (b) $595 \mathrm{~A}-8$ $3,130-136 \mathrm{~cm}, \mathrm{~S} 1.63-2$, W35. 

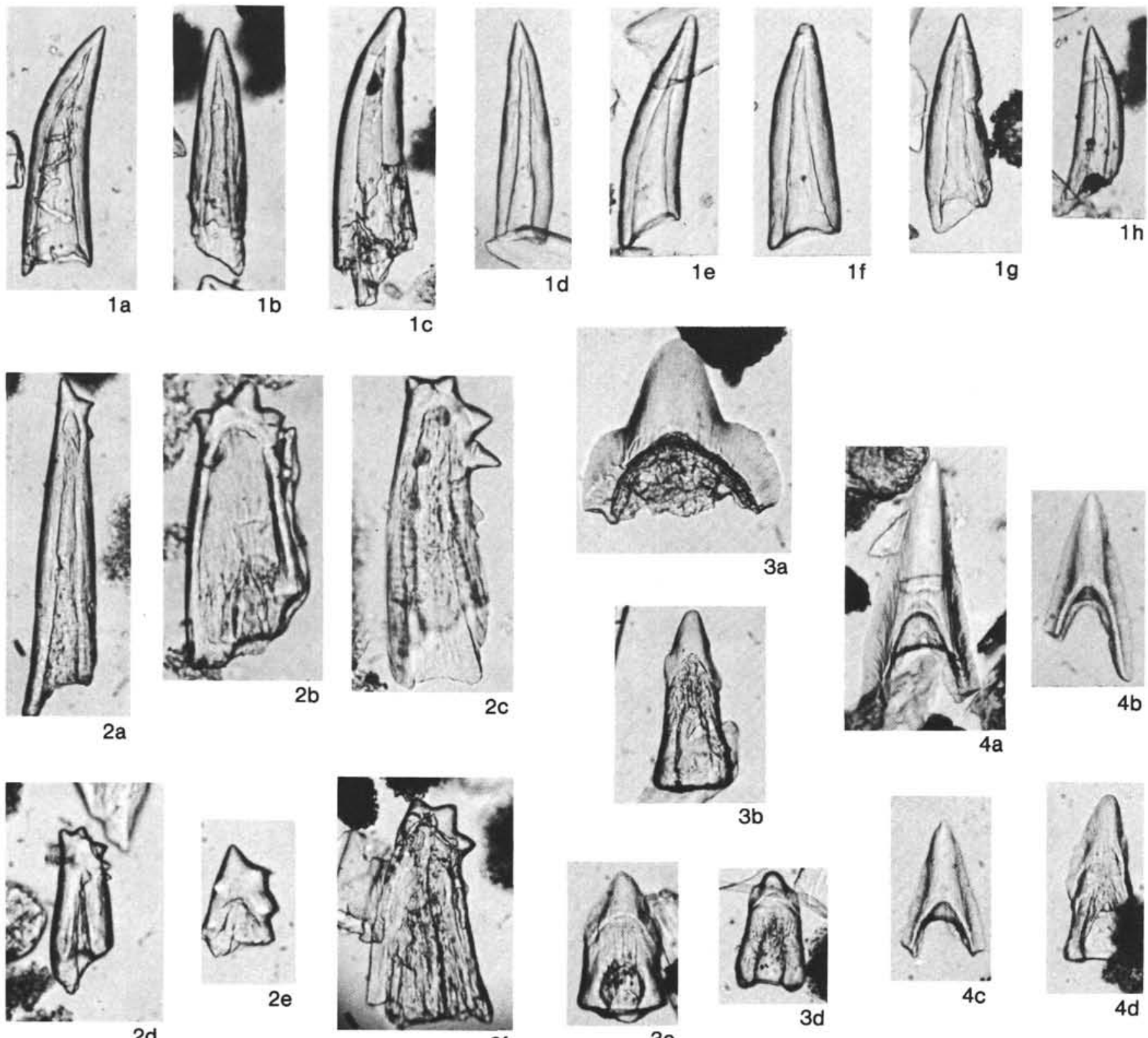

$2 f$
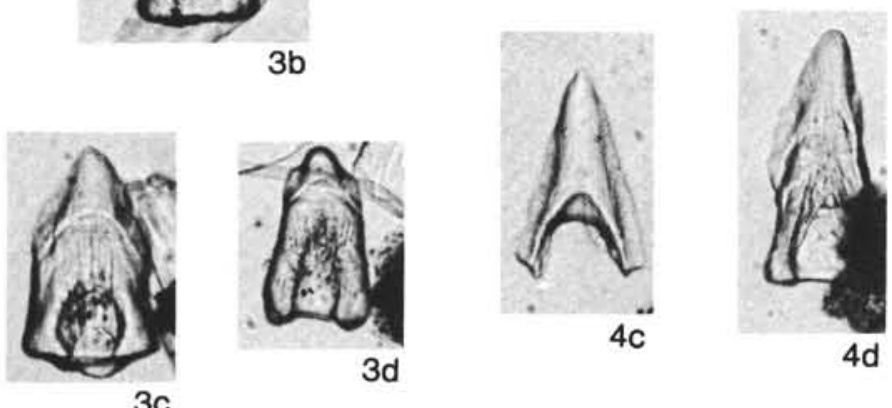

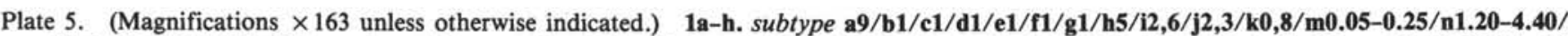
p0/q2,6/r1/s1,2/t1/z0 New subtype Narrow triangle long inline. (a) 596-6-4, 60-66 cm, S1.63-2, D38; (b) 596-6-4, 60-66 cm, S1.63-9, F24; (c) 596-6-4, 60-66 cm, S1.63-1, R10; (d) 595A-5-7, 30-37 cm, S1.63-2, G29; (e) 595A-5-7, 30-37 cm, S1.63-2, G21; (f) 595A-5-7, 30-37 cm, S1.63-1, M16, type specimen; (g) 595A-5-7, 30-37 cm, S1.63-2, C44; (h) 595A-5-7, 30-37 cm, S1.63-3, E41. 2a-f. subtype a9/b5/c3/d1,3,4/e1/f1/g1/ h5/i2/j2/k0/m0/n0/p0/q0/r0/s1,2/t1/z2/cc1/dd1/ee1/ff1/gg1/hh0/jj2/kk2,3/mm0/nn0 New subtype; Triangle many projections. (a) 596-64, 60-66 cm, S1.63-5, H25; (b) 596-5-4, 81-84 cm, S1.63-1, N29, ×267; (c) 596-5,CC, S1.63-5, J19, × 267; (d) 596-5-4, 81-84 cm, S1.63-11, D6, type specimen; (e) 596A-5-1, 82-85 cm, S1.63-1, M22; (f) 596-6-4, 60-66 cm, S1.63-6, Y21. 3a-d. subtype a9/b1,5/c1/d1/e1/f4+8+14/g1/ h5/i4/j4/k5/m0.45-0.85/n0.60-1.30/p1.30-2.30/q0,3,9/r0,1/s3/t1/z0,2,5/cc0,1/dd0,1/ee0,1/ff0,1/gg0,3/hh0.55-0.95/ji2//kk2/mm0/ nn0.35-0.80 New subtype; Triangle with humps. (a) 595A-3-3, 50-52 cm, S1.63-1, X14; (b) 596-6-4, 60-66 cm, S1.63-9, Q24; (c) 596-6-3, 63-67 $\mathrm{cm}, \mathrm{S} 1.63-1, \mathrm{R} 29$; (d) 595A-3-2, 50-55 cm, S1.63-1, S24, type specimen. 4a-d. subtype $\mathrm{a} 9 / \mathrm{b} 1,5 / \mathrm{c1} / \mathrm{d} 1 / \mathrm{e} 1 / \mathrm{f} 4+8+14 / \mathrm{g} 1 / \mathrm{h} 0 / \mathrm{i} 2 / \mathrm{j} 2,3 / \mathrm{k5} / \mathrm{m0.70}$ 1.60/n0.90-1.85/p0.70-1.60/q6,7,8/r1/s1,2/t1/z0,5/cc0,1/dd0,1/ee0,1/fro,1/gg0,1/hh0/jij2/kk2/mm0/nn0 New subtype; Pointed triangle arcuate inline. (a) 596B-1,CC, S1.63-1, L40; (b) 596B-1-2, 79-82 cm, S1.63-1, U36, type specimen; (c) 596B-1-3, 79-82 cm, S1.63-2, K27; (d) 596-6-4, 60-66 cm, S1.63-5, E32. 
E. C. WINFREY, P. S. DOYLE, W. R. RIEDEL
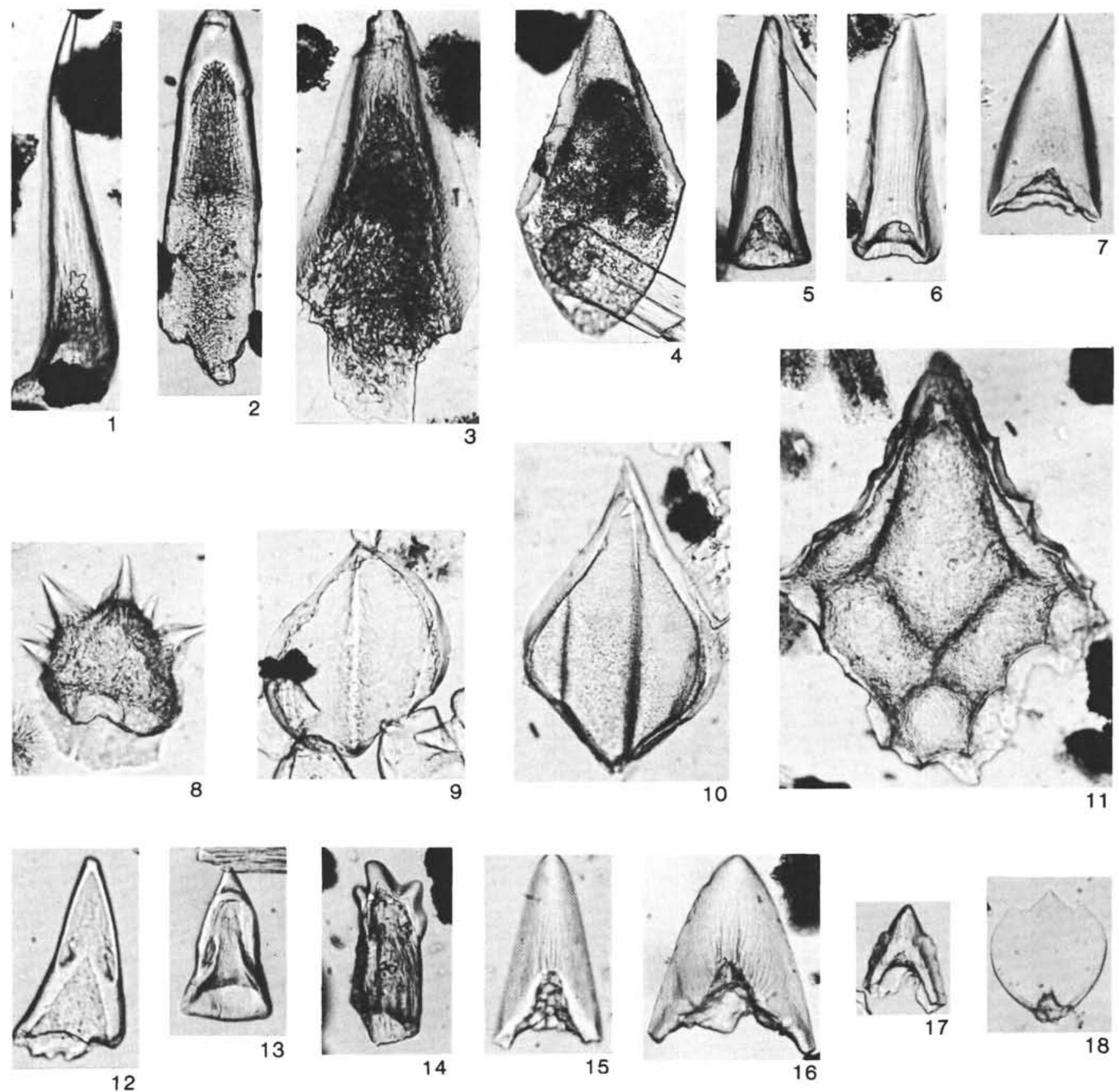

Plate 6. All specimens figured on this plate are undescribed Mesozoic forms. Those with an asterisk are Albian or Late Cretaceous. (Magnifications $\times 163$ unless otherwise indicated.) 1. 595A-8-3, 130-136 cm, S1.63-3, N34; 2. 595A-8-3, 130-136 cm, S1.63-2, O42, × 106; 3.* 5965,CC, S1.63-3, G37; 4. 596A-1-2, 92-98 cm, S1.63-1, Q44, × 106; 5. 595A-5-7, 30-37 cm, S1.63-3, H26; 6.* 596-6-3, 63-67 cm, S1.63-4, Q26; 7. 595A-4-6, 22-27 cm, S1.63-2, C28; 8. 595A-4-6, 22-27 cm, S1.63-4, K19; 9. 595A-3-2, 50-55 cm, S1.63-2, M20; 10.* 596B-1-5, 79-82 cm, S1.1, H18, × 106; 11.* 596-3-4, 108-111 cm, S1.63-1, O25; 12. 596A-1-1, 70-78 cm, S1.63-4, G39; 13. 595A-5-7, 30-37 cm, S1.63-2, A52; 14.* 596-6-1, 85-88 cm, S1.63-1, C26; 15. 595A-8-3, 130-136 cm, S1.63-1, M21; 16. 595A-8-3, 130-136 cm, S1.63-2, L24; 17. $595 \mathrm{~A}-4-4,24-29 \mathrm{~cm}, \mathrm{~S} 1.63-1, \mathrm{~S} 14$; 18. $596 \mathrm{~B}-1-1,79-82 \mathrm{~cm}, \mathrm{~S} 1.63-1, \mathrm{O} 37$. 